\title{
FPLUME-1.0: An integral volcanic plume model accounting for ash aggregation
}

\author{
A. Folch ${ }^{1}$, A. Costa ${ }^{2}$, and G. Macedonio ${ }^{3}$ \\ ${ }^{1}$ CASE Department, Barcelona Supercomputing Center, Barcelona, Spain \\ ${ }^{2}$ Istituto Nazionale di Geofisica e Vulcanologia, Sezione di Bologna, Bologna, Italy \\ ${ }^{3}$ Istituto Nazionale di Geofisica e Vulcanologia, Sezione di Napoli, Naples, Italy
}

Correspondence to: A. Folch (arnau.folch@bsc.es)

Received: 22 July 2015 - Published in Geosci. Model Dev. Discuss.: 17 September 2015

Revised: 22 December 2015 - Accepted: 5 January 2016 - Published: 2 February 2016

\begin{abstract}
Eruption source parameters (ESP) characterizing volcanic eruption plumes are crucial inputs for atmospheric tephra dispersal models, used for hazard assessment and risk mitigation. We present FPLUME-1.0, a steady-state 1-D (one-dimensional) cross-section-averaged eruption column model based on the buoyant plume theory (BPT). The model accounts for plume bending by wind, entrainment of ambient moisture, effects of water phase changes, particle fallout and re-entrainment, a new parameterization for the air entrainment coefficients and a model for wet aggregation of ash particles in the presence of liquid water or ice. In the occurrence of wet aggregation, the model predicts an effective grain size distribution depleted in fines with respect to that erupted at the vent. Given a wind profile, the model can be used to determine the column height from the eruption mass flow rate or vice versa. The ultimate goal is to improve ash cloud dispersal forecasts by better constraining the ESP (column height, eruption rate and vertical distribution of mass) and the effective particle grain size distribution resulting from eventual wet aggregation within the plume. As test cases we apply the model to the eruptive phase-B of the 4 April 1982 El Chichón volcano eruption (México) and the 6 May 2010 Eyjafjallajökull eruption phase (Iceland). The modular structure of the code facilitates the implementation in the future code versions of more quantitative ash aggregation parameterization as further observations and experiment data will be available for better constraining ash aggregation processes.
\end{abstract}

\section{Introduction}

Volcanic plumes (e.g. Sparks, 1997) are turbulent multiphase flows containing volcanic gas, entrained ambient air and moisture and tephra, consisting on both juvenile (resulting from magma fragmentation), crystal and lithic (resulting from wall rock erosion) particles ranging from metre-sized blocks to micron-sized fine ash (diameter $\leq 63 \mu \mathrm{m}$ ). Sustained volcanic plumes present a negatively buoyant basal thrust region where the mixture rises due to its momentum. As ambient air is entrained by turbulent mixing, it heats and expands, thereby reducing the average density of the mixture. It leads to a transition to the convective region, in which positive buoyancy drives the mixture up to the so-called neutral buoyancy level (NBL), where the mixture density equals that of the surrounding atmosphere. Excess of momentum above the NBL (overshooting) can drive the mixture higher forming the umbrella region, where tephra disperses horizontally first as a gravity current (e.g. Costa et al., 2013; Carazzo et al., 2014) and then under passive wind advection forming a volcanic cloud (see Fig. 1).

Quantitative observations and models of volcanic plumes are essential to provide realistic source terms to atmospheric dispersal models, aimed at simulating atmospheric tephra transport and/or the resulting fallout deposit (e.g. Folch, 2012). Plume models range in complexity from 1-D (onedimensional) integral models built upon the buoyant plume theory (BPT) of Morton et al. (1956) to sophisticated multiphase Computational Fluid Dynamics (CFD) models (e.g. Suzuki et al., 2005; Esposti Ongaro et al., 2007; Suzuki and Koyaguchi, 2009; Herzog and Graf, 2010; Suzuki and Koyaguchi, 2013). The latter group of models are valuable to understand physical phenomena and the role of different param- 


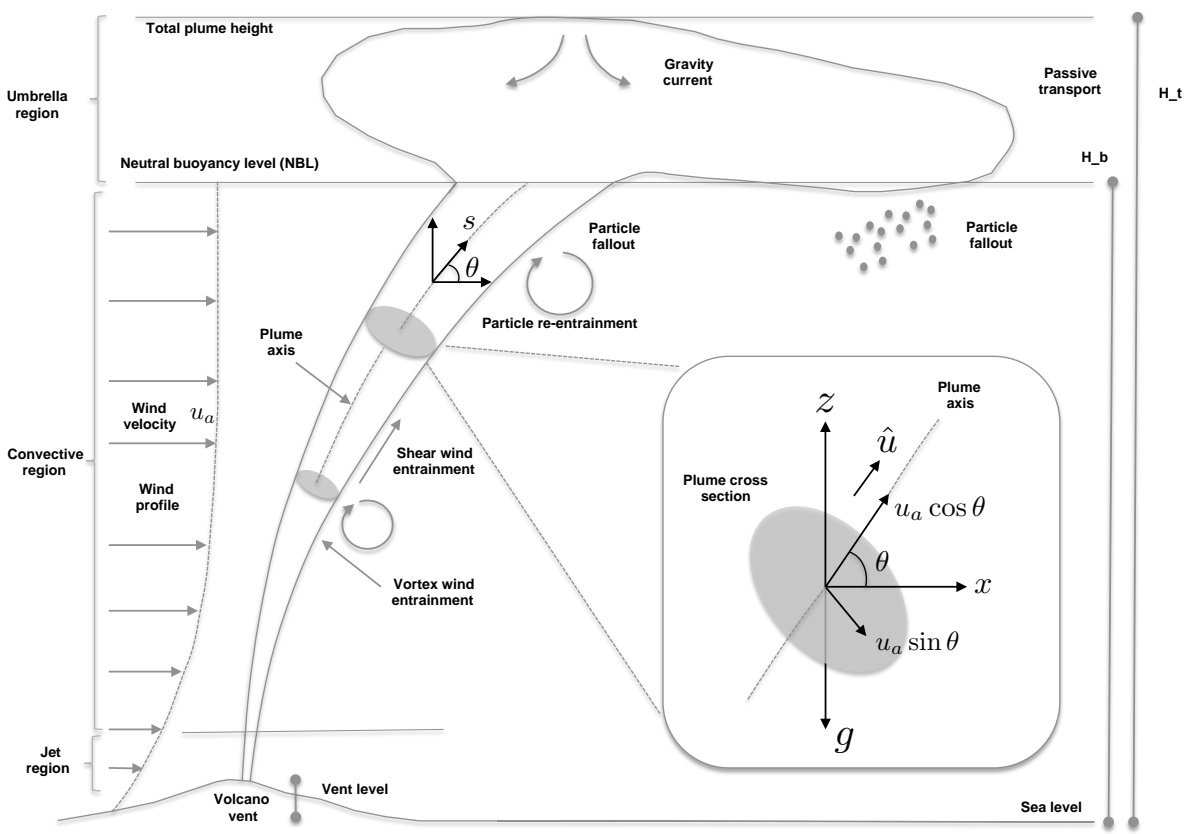

Figure 1. Sketch of an axisymmetric volcanic plume raising in a wind profile. Three different regions (jet thrust, convective thrust and umbrella) are indicated, with the convective region reaching a height $H_{\mathrm{b}}$ (that of the neutral buoyancy level), and the umbrella region raising up to $H_{t}$ above the sea level (a.s.l.). The inset plot details a plume cross section perpendicular to the plume axis, inclined of an angle $\theta$ with respect to the horizontal.

eters but, given their high computational cost, coupling with atmospheric dispersal models at an operational level is still unpractical. Moreover, even sophisticated 3-D multiphase models can have serious problems to accurately describe the physical processes related to closure equations, computational spatial resolution, etc. For this reason, simpler 1$\mathrm{D}$ cross-section-averaged models or even empirical relationships between plume height and eruption rate (e.g. Mastin et al., 2009; Degruyter and Bonadonna, 2012) are used in practice to furnish eruption source parameters (ESP) to atmospheric transport models, the results of which strongly depend on the source term quantification (i.e. determination of plume height, eruption rate, vertical distribution of mass and particle grain size distribution).

Many plume models based on the BPT have been proposed after the seminal studies of Wilson (1976) and Sparks (1986) to address different aspects of plume dynamics. For example, Woods (1993) proposed a model to include the latent heat associated with condensation of water vapour and quantify its effects upon the eruption column. Ernst et al. (1996) presented a model considering particle sedimentation and re-entrainment from plume margins. Bursik (2001) analysed how the interaction with wind enhances entrainment of air, plume bending and decrease of the total plume height for a given eruption rate. Several other plume models exist (see Costa et al., 2015, and references therein), considering different modelling approaches, simplifying assumptions and model parameterizations. It is well recognized that the values of the air entrainment coefficients have a large influence on the results of the plume models. On the other hand, volcanic ash aggregation (e.g. Brown et al., 2012) can occur within the eruption column or, under certain circumstances, downstream within the ash cloud (Durant et al., 2009). In any case, the formation of ash aggregates (with typical sizes around few hundreds of $\mu \mathrm{m}$ and less dense than the primary particles) dramatically impacts particle transport dynamics thereby reducing the atmospheric residence time of aggregating particles and promoting the premature fallout of fine ash. As a result, atmospheric transport models neglecting aggregation tend to overestimate far-range ash cloud concentrations, leading to an overestimation of the risk posed by ash clouds on civil aviation and an underestimation of ash loading in the near field. So far, no plume model tries to predict the formation of ash aggregates in the eruptive column and how it affects the particle grain size distribution erupted at the vent. This can be explained in part because aggregation mechanisms are complex and not fully understood yet, although theoretical models have been proposed for wet aggregation (Costa et al., 2010; Folch et al., 2010).

Here we present FPLUME-1.0, a steady-state 1-D crosssection-averaged plume model, which accounts for plume bending, entrainment of ambient moisture, effects of water phase changes on the energy budget, particle fallout and reentrainment by turbulent eddies, variable entrainment coefficients fitted from experiments and particle aggregation in presence of liquid water or ice that depends on plume dy- 
namics, particle properties, and amount of liquid water and ice existing in the plume. The modelling of aggregation in the plume, proposed here for the first time, allows our model to predict an effective total grain size distribution (TGSD) depleted in fines with respect to that erupted at the vent. The ultimate goal is to improve ash cloud forecasts by better constraining these relevant aspects of the source term. In this manuscript, we present first the governing equations for the plume and aggregation models and then apply the combined model to two test cases, the eruptive phase-B of the $1982 \mathrm{El}$ Chichón volcano eruption (México) and the 6 May 2010 Eyjafjallajökull eruption phase (Iceland).

\section{Physical plume model}

We consider a volcanic plume as a multiphase mixture of volatiles, suspended particles (tephra) and entrained ambient air. For simplicity, water (in vapour, liquid or ice phase) is assumed the only volatile species, being either of magmatic origin or incorporated through the ingestion of moist ambient air. Erupted tephra particles can form by magma fragmentation or by erosion of the volcanic conduit, and can vary notably in size, shape and density. For historical reasons, field volcanologists describe the continuous spectrum of particle sizes in terms of the dimensionless $\Phi$-scale (Krumbein, 1934):

$d(\Phi)=d_{*} 2^{-\Phi}=d_{*} e^{-\Phi \log 2}$,

where $d$ is the particle size and $d_{*}=10^{-3} \mathrm{~m}$ is a reference length (i.e. $2^{-\Phi}$ is the direction-averaged particle size expressed in $\mathrm{mm}$ ). The vast majority of modelling strategies, discretize the continuous particle grain size distribution (GSD) by grouping particles in $n$ different $\Phi$-bins, each with an associated particle mass fraction (the models based on moments (e.g. de' Michieli Vitturi et al., 2015) are the exception). Because particle size exerts a primary control on sedimentation, $\Phi$-classes are often identified with terminal settling velocity classes although, strictly, a particle settling velocity class is defined not only by particle size but also by its density and shape. We propose a model for volcanic plumes as a multiphase homogeneous mixture of water (in any phase), entrained air, and $n$ particle classes, including a parameterization for the air entrainment coefficients and a wet aggregation model. Because the governing equations based upon the BPT are not adequate above NBL, we also propose a new semi-empirical model to describe such a region.

\subsection{Governing equations}

The steady-state cross-section-averaged governing equations for axisymmetric plume motion in a turbulent wind (see
Fig. 1) are the following (for the meaning of the used symbols see Tables 1 and 2):

$$
\begin{aligned}
& \frac{d \hat{M}}{d s}=2 \pi r \rho_{\mathrm{a}} u_{\mathrm{e}}+\sum_{i=1}^{n} \frac{d \hat{M}_{i}}{d s}, \\
& \frac{d \hat{P}}{d s}=\pi r^{2}\left(\rho_{\mathrm{a}}-\hat{\rho}\right) g \sin \theta+u_{\mathrm{a}} \cos \theta\left(2 \pi r \rho_{\mathrm{a}} u_{\mathrm{e}}\right) \\
& +\hat{u} \sum_{i=1}^{n} \frac{d \hat{M}_{i}}{d s},
\end{aligned}
$$

$\hat{P} \frac{d \theta}{d s}=\pi r^{2}\left(\rho_{\mathrm{a}}-\hat{\rho}\right) g \cos \theta-u_{\mathrm{a}} \sin \theta\left(2 \pi r \rho_{\mathrm{a}} u_{\mathrm{e}}\right)$,

$$
\begin{aligned}
& \frac{d \hat{E}}{d s}=2 \pi r \rho_{\mathrm{a}} u_{\mathrm{e}}\left(\left(1-w_{\mathrm{a}}\right) c_{\mathrm{a}} T_{\mathrm{a}}+w_{\mathrm{a}} h_{\mathrm{wa}}\left(T_{\mathrm{a}}\right)+g z+\frac{1}{2} u_{\mathrm{e}}^{2}\right) \\
& +c_{\mathrm{p}} \hat{T} \sum_{i=1}^{n} \frac{d \hat{M}_{i}}{d s},
\end{aligned}
$$

$\frac{d \hat{M}_{\mathrm{a}}}{d s}=2 \pi r \rho_{\mathrm{a}} u_{\mathrm{e}}\left(1-w_{\mathrm{a}}\right)$,

$\frac{d \hat{M}_{w}}{d s}=2 \pi r \rho_{\mathrm{a}} u_{\mathrm{e}} w_{\mathrm{a}}$,

$\frac{d \hat{M}_{i}}{d s}=-\frac{\chi u_{\mathrm{s} i}}{r \hat{u}}\left(1+\frac{f u_{\mathrm{e}}}{u_{\mathrm{s} i} d r / d s}\right)^{-1} \hat{M}_{i}+A_{i}^{+}-A_{i}^{-}$,

$\frac{d x}{d s}=\cos \theta \cos \Phi_{\mathrm{a}}$,

$\frac{d y}{d s}=\cos \theta \sin \Phi_{\mathrm{a}}$,

$\frac{d z}{d s}=\sin \theta$,

where $\hat{M}=\pi r^{2} \hat{\rho} \hat{u}$ is the total mass flow rate, $\hat{P}=\hat{M} \hat{u}$ is the total axial (stream-wise) momentum flow rate, $\theta$ is the plume bent over angle with respect to the horizontal (i.e. $\theta=90^{\circ}$ for a plume raising vertically), $\hat{E}=\hat{M}\left(\hat{H}+g z+\frac{1}{2} \hat{u}^{2}\right)$ is the total energy flow rate, $\hat{H}$ is the enthalpy flow rate of the mixture, $\hat{T}=\hat{T}(\hat{H})$ is the mixture temperature, $\hat{M}_{\mathrm{a}}$ is the mass flow rate of dry air, $\hat{M}_{w}=\hat{M} \hat{x}_{w}$ is the mass flow rate of volatiles (including water vapour, liquid and ice), $h_{\mathrm{wa}}$ is the enthalpy 
Table 1. List of Latin symbols. Quantities with a hat denote bulk (top-hat averaged) quantities. Throughout the text, the subindex o (e.g. $\hat{M}_{o}$, $\left.\hat{u}_{o}\right)$ indicates values of quantities at the vent $(s=0)$.

\begin{tabular}{|c|c|c|c|}
\hline Symbol & Definition & Units & Comments \\
\hline$A_{i}^{+}\left(A_{i}^{-}\right)$ & Aggregation source (sink) terms & $\mathrm{kgs}^{-1} \mathrm{~m}^{-1}$ & Given by Eqs. (28) and (29) \\
\hline$A_{\mathrm{B}}$ & Collision frequency by Brownian motion & $\mathrm{m}^{3} \mathrm{~s}^{-1}$ & Given by Eq. (41a) \\
\hline$A_{\mathrm{DS}}$ & Collision frequency by differential sedimentation & $\mathrm{m}^{-1} \mathrm{~s}^{-1}$ & Given by Eq. (41c) \\
\hline$A_{\mathrm{S}}$ & Collision frequency by fluid shear & $\mathrm{s}^{-1}$ & Given by Eq. (41b) \\
\hline$A_{\mathrm{TI}}$ & Collision frequency by turbulent inertia & $\mathrm{m}^{3} \mathrm{~s}^{-1}$ & Given by Eq. (41d) \\
\hline$c_{\mathrm{a}}$ & Specific heat capacity of air at constant pressure & $\mathrm{J} \mathrm{kg}^{-1} \mathrm{~K}^{-1}$ & Default value 1000 \\
\hline$c_{1}$ & Specific heat capacity of liquid water & $\mathrm{J} \mathrm{kg}^{-1} \mathrm{~K}^{-1}$ & Default value 4200 \\
\hline$c_{\mathrm{p}}$ & Specific heat capacity of particles (pyroclasts) & $\mathrm{J} \mathrm{kg}^{-1} \mathrm{~K}^{-1}$ & Default value 1600 \\
\hline$c_{\mathrm{S}}$ & Specific heat capacity of solid water (ice) & $\mathrm{J} \mathrm{kg}^{-1} \mathrm{~K}^{-1}$ & Default value 2000 \\
\hline$c_{\mathrm{V}}$ & Specific heat capacity of water vapour & $\mathrm{J} \mathrm{kg}^{-1} \mathrm{~K}^{-1}$ & Default value 1900 \\
\hline$C_{\mathrm{d}}$ & Particle drag coefficient & - & Given by Eq. (15) \\
\hline$\hat{C}_{i}$ & Mass concentration of particles of class $i$ & $\mathrm{kgm}^{-3}$ & Given by Eq. (43) \\
\hline$D_{f}$ & Fractal exponent & - & Values between 2.8 and 3 (Costa et al., 2010) \\
\hline$d_{\mathrm{A}}$ & Diameter of the aggregates & $\mathrm{m}$ & One single aggregated class is assumed \\
\hline$d_{i}$ & Diameter of particles of class $i$ & $\mathrm{~m}$ & Sphere equivalent diameter for irregular shapes \\
\hline$e_{1}$ & Saturation pressure of water vapour over liquid & $\mathrm{Pa}$ & Given by Eq. (9) \\
\hline$e_{\mathrm{S}}$ & Saturation pressure of water vapour over solid (ice) & $\mathrm{Pa}$ & Given by Eq. (10) \\
\hline$\hat{E}$ & Energy flow rate & $\mathrm{kg} \mathrm{m}^{2} \mathrm{~s}^{-3}$ & $\hat{E}=\hat{M}\left(\hat{c} \hat{T}+g z+\frac{1}{2} \hat{u}^{2}\right)$ \\
\hline$\hat{f}$ & Correction factor for aggregation & - & See Appendix A. Values between 2-4. \\
\hline$f$ & Particle re-entrainment parameter & - & Given by Eq. (13) \\
\hline$f_{i}$ & Mass fraction of particle class $i$ & - & $\sum f_{i}=1$ \\
\hline$g$ & Gravitational acceleration & $\mathrm{ms}^{-2}$ & Value of 9.81 \\
\hline$h_{1}$ & Enthalpy per unit mass of liquid water & $\mathrm{J} \mathrm{kg}^{-1}$ & Given by Eq. (6b) \\
\hline$h_{\mathrm{S}}$ & Enthalpy per unit mass of ice & $\mathrm{J} \mathrm{kg}^{-1}$ & Given by Eq. (6a) \\
\hline$h_{\mathrm{v}}$ & Enthalpy per unit mass of vapour & $\mathrm{J} \mathrm{kg}^{-1}$ & Given by Eq. (6c) \\
\hline$h_{l 0}$ & Enthalpy per unit mass of liquid water at $T=T_{0}$ & $\mathrm{~J} \mathrm{~kg}^{-1}$ & \\
\hline$h_{s 0}$ & Enthalpy per unit mass of ice at $T=T_{0}$ & $\mathrm{~J} \mathrm{~kg}^{-1}$ & \\
\hline$h_{v 0}$ & Enthalpy per unit mass of vapour at $T=T_{0}$ & $\mathrm{~J} \mathrm{~kg}^{-1}$ & \\
\hline$h_{\mathrm{wa}}$ & Enthalpy per unit mass of water in the atmosphere & $\mathrm{J} \mathrm{kg}^{-1}$ & See Eq. $(2 d)$ \\
\hline$\hat{M}$ & Total mass flow rate & $\mathrm{kg} \mathrm{s}^{-1}$ & $\hat{M}=\pi r^{2} \hat{\rho} \hat{u}=\sum \hat{M}_{i}+\hat{M}_{w}+\hat{M}_{\mathrm{a}}$ \\
\hline$\hat{M}_{\mathrm{a}}$ & Mass flow rate of dry air & $\mathrm{kg} \mathrm{s}^{-1}$ & \\
\hline$\hat{M}_{i}$ & Mass flow rate of particles of class $i$ & $\mathrm{~kg} \mathrm{~s}^{-1}$ & $\hat{M}_{i}=\hat{M} \hat{x}_{\mathrm{p}} f_{i}$ \\
\hline$\hat{M}_{w}$ & Mass flow rate of volatiles (water in any phase) & $\mathrm{kg} \mathrm{s}^{-1}$ & $\hat{M}_{w}=\hat{M} \hat{x}_{w}$ \\
\hline$N_{i}$ & Number of particles of diameter $d_{i}$ in an aggregate & - & Given by Eq. (31) \\
\hline$\dot{n}_{i}$ & Number of aggregating particles per unit volume and time & $\mathrm{m}^{-3} \mathrm{~s}^{-1}$ & Given by Eq. (30) \\
\hline$\dot{n}_{\text {tot }}$ & Total particle decay per unit volume and time & $\mathrm{m}^{-3} \mathrm{~s}^{-1}$ & Given by Eq. (34) \\
\hline$n_{\text {tot }}$ & Number of particles per unit volume available for aggregation & $\mathrm{m}^{-3}$ & Given by Eq. (42) \\
\hline$\hat{P}$ & Axial (stream-wise) momentum flow rate & $\mathrm{kg} \mathrm{ms}^{-2}$ & $\hat{P}=\hat{M} \hat{u}$ \\
\hline$P$ & Pressure & $\mathrm{Pa}$ & \\
\hline$P_{\mathrm{V}}$ & Partial pressure of water vapour & $\mathrm{Pa}$ & Given by Eq. (8a) \\
\hline$r$ & Cross section plume radius & $\mathrm{m}$ & Axial symmetry is assumed \\
\hline$s$ & Distance along the plume axis & $\mathrm{m}$ & Equations integrated from $s=0$ to the NBL \\
\hline$\hat{T}$ & Mixture temperature & $\mathrm{K}$ & Thermal equilibrium is assumed \\
\hline$T_{\mathrm{a}}$ & Ambient air temperature & K & Assumed to vary only with $z$ \\
\hline$T_{f}$ & Freezing temperature & K & Value of $255(-18 \mathrm{C})$ assumed \\
\hline$\hat{u}$ & Mixture velocity along the plume axis & $\mathrm{ms}^{-1}$ & Mechanical equilibrium is assumed \\
\hline$u_{\mathrm{a}}$ & Horizontal wind (air) velocity & $\mathrm{ms}^{-1}$ & Assumed to vary only with $z$ \\
\hline$u_{\mathrm{e}}$ & Air entrainment velocity (by turbulent eddies) & $\mathrm{ms}^{-1}$ & Given by Eq. (17) \\
\hline$u_{\mathrm{s} i}$ & Terminal settling velocity of particle class $i$ & $\mathrm{~ms}^{-1}$ & Given by Eq. (14) \\
\hline$w_{\mathrm{a}}$ & Mass fraction of water in the entrained ambient air & - & Specific humidity $(\mathrm{kg} / \mathrm{kg})$ \\
\hline$x$ & Horizontal coordinate & $\mathrm{m}$ & \\
\hline$\hat{x}_{1}$ & Mass fraction of liquid water & - & \\
\hline$\hat{x}_{\mathrm{s}}$ & Mass fraction of solid water (ice) & - & \\
\hline$\hat{x}_{\mathrm{V}}$ & Mass fraction of water vapour & - & \\
\hline$\hat{x}_{\mathrm{p}}$ & Mass fraction of particles (pyroclasts) & - & Given by Eq. (4) \\
\hline$\hat{x}_{w}$ & Mass fraction of volatiles (water) & - & $\hat{x}_{w}=\hat{x}_{\mathrm{v}}+\hat{x}_{1}+\hat{x}_{\mathrm{s}}$ \\
\hline$y$ & Horizontal coordinate & $\mathrm{m}$ & \\
\hline$z$ & Vertical coordinate & $\mathrm{m}$ & Typically given a.s.l. or a.v.l. \\
\hline$z_{\mathrm{s}}$ & Dimensionless height & - & $z_{\mathrm{s}}=z / 2 r_{o}$ \\
\hline
\end{tabular}


Table 2. List of greek symbols. Quantities with a hat denote bulk (top-hat averaged) quantities.

\begin{tabular}{|c|c|c|c|}
\hline Symbol & Definition & Units & Comments \\
\hline$\alpha_{\mathrm{m}}$ & Class-averaged particle sticking efficiency & - & Given by Eq. (44) \\
\hline$\alpha_{i j}$ & Sticking efficiency between particles of class $i$ and $j$ & - & Given by Eq. (45) \\
\hline$\alpha_{\mathrm{s}}$ & stream-wise (shear) air entrainment coefficient & - & Given by Eq. (19) \\
\hline$\alpha_{\mathrm{V}}$ & cross-flow (vortex) air entrainment coefficient & - & Given by Eq. (21) \\
\hline$\epsilon$ & Dissipation rate of turbulent kinetic energy & $m^{2} s^{-3}$ & Given by Eq. (37) \\
\hline$\Gamma_{\mathrm{s}}$ & Fluid shear & $\mathrm{s}^{-1}$ & Given by Eq. (39) \\
\hline$\phi$ & Volume fraction of particles & - & \\
\hline$\hat{\mu}$ & Mixture dynamic viscosity & $\mathrm{Pa} \mathrm{s}$ & Assumed equal to that of air at bulk temperature \\
\hline$\mu_{1}$ & Liquid water dynamic viscosity & Pas & \\
\hline$\hat{v}$ & Mixture kinematic viscosity & $\mathrm{m}^{2} \mathrm{~s}^{-1}$ & $\hat{v}=\hat{\mu} / \hat{\rho}$ \\
\hline$\hat{\rho}$ & Mixture density & $\mathrm{kg} \mathrm{m}^{-3}$ & Given by Eq. (3) \\
\hline$\rho_{\mathrm{a}}$ & Ambient air density & $\mathrm{kg} \mathrm{m}^{-3}$ & Assumed to vary only with $z$ \\
\hline$\rho_{1}$ & Liquid water density & $\mathrm{kg} \mathrm{m}^{-3}$ & Value of 1000 \\
\hline$\rho_{g}$ & Gas phase (dry air plus water vapour) density & $\mathrm{kg} \mathrm{m}^{-3}$ & \\
\hline$\rho_{\mathrm{p}}$ & Class-averaged particle (pyroclasts) density & $\mathrm{kg} \mathrm{m}^{-3}$ & $\rho_{\mathrm{p}}=\sum f_{i} \rho_{p i}$ \\
\hline$\rho_{p i}$ & Density of particles of class $i$ & $\mathrm{~kg} \mathrm{~m}^{-3}$ & \\
\hline$\rho_{\mathrm{s}}$ & Ice density & $\mathrm{kg} \mathrm{m}^{-3}$ & Value of 920 \\
\hline$\phi$ & Solid (particles) volume fraction & - & $\phi=\sum \hat{C}_{i} / \rho_{p i}$ \\
\hline$\Phi$ & Dimensionless number related to size & - & Given by Eq. (1) \\
\hline$\Phi_{\mathrm{a}}$ & Horizontal wind direction (azimuth) & $\mathrm{rad}$ & \\
\hline$\Psi$ & Particle sphericity & - & $\Psi=1$ for spheres \\
\hline$\theta$ & Plume bent over angle with respect to the horizontal & $\mathrm{rad}$ & \\
\hline$\xi$ & Diameter to volume fractal relationship & - & \\
\hline$\chi$ & Constant giving the probability of fallout & - & Value of $\approx 0.23$ (Bursik, 2001) \\
\hline
\end{tabular}

per unit mass of the water in the atmosphere, $\hat{M}_{i}=\hat{M} \hat{x}_{\mathrm{p}} f_{i}$ is the mass flow rate of particles of class $i(i=1: n), x$ and $y$ are the horizontal coordinates, $z$ is height and $s$ is the distance along the plume axis (see Tables 1 and 2 for the definition of all symbols and variables appearing in the manuscript).

The equations above derive from conservation principles assuming axial (stream-wise) symmetry and considering bulk quantities integrated over a plume cross section using a top-hat profile in which a generic quantity $\phi$ has a constant value $\hat{\phi}(s)$ at a given plume cross section and vanishes outside (here we refer to section-averaged quantities as bulk quantities, denoted by a hat). We have derived these equations by combining formulations from different previous plume models (Netterville, 1990; Woods, 1993; Ernst et al., 1996; Bursik, 2001; Costa et al., 2006; Woodhouse et al., 2013) in order to include in a single model effects from plume bending by wind, particle fallout and re-entrainment at plume margins, transport of volatiles (water) accounting also for ingestion of ambient moisture, phase changes (water vapour condensation and deposition) and particle aggregation. Equation $(2 \mathrm{j})$ expresses the conservation of total mass, accounting in the right-hand side (rhs) for the mass of air entrained through the plume margins and the loss/gain of mass by particle fallout/re-entrainment. Equation (2b) and (2c) express the conservation of axial (stream-wise) and radial momentum, respectively, accounting on the rhs for con- tributions from buoyancy (first term), entrainment of air, and particle fallout/re-entrainment. Note that generally the buoyancy term, acting only along the vertical direction $z$, represents a sink of momentum in the basal gas-thrust jet region (where $\hat{\rho}>\rho_{\mathrm{a}}$ ) and a source of momentum where the plume is positively buoyant $\left(\hat{\rho}<\rho_{\mathrm{a}}\right)$. Equation $(2 \mathrm{~d})$ expresses the conservation of energy, accounting on the rhs for gain of energy (enthalpy, potential and kinetic) by ambient air entrainment (first term), loss/gain by particle fallout/re-entrainment (second term), and gain of energy by conversion of water vapour into liquid (condensation) or into ice (deposition). Equation (2e), (2f) and (2g) express, respectively, the conservation of mass of dry air, water (vapour, liquid and ice) and solid particles. The latter set of equations, one for each particle class, account on the rhs for particle re-entrainment (first term), particle fallout (second term) and particle aggregation. Here we have included to terms $\left(A_{i}^{+}\right.$and $\left.A_{i}^{-}\right)$that account for the creation of mass from smaller particles aggregating into particle class $i$ and for the destruction of mass resulting from particles of class $i$ contributing to the formation of largersize aggregates. Finally, Eq. (2h) to $(2 \mathrm{j})$ determine the $3-\mathrm{D}$ plume trajectory as a function of the length parameter $s$. All these equations constitute a set of $9+n$ first order ordinary differential equations in $s$ for $9+n$ unknowns: $\hat{M}, \hat{P}, \theta, \hat{E}$, $\hat{M}_{\mathrm{a}}, \hat{M}_{w}, \hat{M}_{i}$ (for each particle class), $x, y$ and $z$. Note that, 
using the definitions of $\hat{M}-\hat{P}-\hat{E}$, the equations can also be expressed in terms of $\hat{u}-r-\hat{T}$ given the bulk density.

Assuming an homogeneous mixture, the bulk density $\hat{\rho}$ of the mixture is

$\frac{1}{\hat{\rho}}=\frac{\hat{x}_{\mathrm{p}}}{\rho_{\mathrm{p}}}+\frac{\hat{x}_{1}}{\rho_{1}}+\frac{\hat{x}_{\mathrm{s}}}{\rho_{\mathrm{s}}}+\frac{\left(1-\hat{x}_{\mathrm{p}}-\hat{x}_{1}-\hat{x}_{\mathrm{s}}\right)}{\rho_{g}}$,

where $\hat{x}_{\mathrm{p}}, \hat{x}_{1}$ and $\hat{x}_{\mathrm{s}}$ are, respectively, the mass fractions of particles, liquid water and ice, $\rho_{\mathrm{p}}$ is the class-weighted average density of particles (pyroclasts), $\rho_{\mathrm{l}}$ and $\rho_{\mathrm{S}}$ are liquid water and ice densities, and $\rho_{g}$ is the gas phase (i.e. dry air plus water vapour) density. Under the assumption of mechanical equilibrium (i.e. assuming the same bulk velocity $\hat{u}$ for all phases and components) it holds that

$\hat{x}_{\mathrm{p}}=\frac{\sum \hat{M}_{i}}{\hat{M}}=\frac{\sum \hat{M}_{i}}{\sum \hat{M}_{i}+\hat{M}_{w}+\hat{M}_{\mathrm{a}}}$.

The enthalpy flow rate of the mixture is a non-decreasing function of the temperature $\hat{T}$ given by

$\hat{H}=\hat{M}\left[x_{\mathrm{a}} c_{\mathrm{a}} \hat{T}+x_{\mathrm{p}} c_{\mathrm{p}} \hat{T}+x_{\mathrm{v}} h_{\mathrm{v}}(\hat{T})+x_{1} h_{1}(\hat{T})+x_{\mathrm{s}} h_{\mathrm{s}}(\hat{T})\right]$,

where $h_{\mathrm{v}}, h_{1}$ and $h_{\mathrm{s}}$ are, respectively, the enthalpy per unit mass of water vapour, liquid and ice:

$h_{\mathrm{S}}(\hat{T})=c_{\mathrm{S}} \hat{T}$,

$h_{1}(\hat{T})=h_{l 0}+c_{1}\left(\hat{T}-T_{0}\right)$

$h_{\mathrm{v}}(\hat{T})=h_{v 0}+c_{\mathrm{v}}\left(\hat{T}-T_{0}\right)$,

where $c_{\mathrm{S}}=2108 \mathrm{~J} \mathrm{~K}^{-1} \mathrm{~kg}^{-1}$ is the specific heat of ice, $T_{0}$ is a reference temperature, $h_{l 0}=3.337 \times 10^{5} \mathrm{~J} \mathrm{~kg}^{-1}$ is the enthalpy of the liquid water at the reference temperature, $c_{1}=$ $4187 \mathrm{~J} \mathrm{~K}^{-1} \mathrm{~kg}^{-1}$ is the specific heat of liquid water, $h_{v 0}=$ $2.501 \times 10^{6} \mathrm{~J} \mathrm{~kg}^{-1}$ is the enthalpy of vapour water at the reference temperature and $c_{\mathrm{V}}=1996 \mathrm{~J} \mathrm{~K}^{-1} \mathrm{~kg}^{-1}$ is the specific heat of vapour water. For convenience, the reference temperature $T_{0}$ is taken equal to the temperature of triple point of the water $\left(T_{0}=273.15 \mathrm{~K}\right)$. The energy and the enthalpy flow rate are related by

$\hat{E}=\hat{H}+\hat{M}\left(g z+\frac{1}{2} u^{2}\right)$

For the integration of Eq. (2d) and for evaluating the aggregation rate terms in Eq. ( $2 \mathrm{~g})$, the temperature $\hat{T}$ and the mass fractions of ice $\left(x_{\mathrm{s}}\right)$, liquid water $\left(x_{1}\right)$ and vapour $\left(x_{\mathrm{V}}\right)$ need to be evaluated. These quantities are obtained by the direct inversion of Eq. (5), with the use of Eqs. (2d) and (7) and by assuming that the pressure inside the plume $P$ is equal to the atmospheric pressure at the same altitude $(z)$.
The model uses a pseudo-gas assumption considering that the mixture of air and water vapour behaves as an ideal gas:

$P=P_{\mathrm{v}}+P_{\mathrm{a}} ; \quad P_{\mathrm{v}}=n_{\mathrm{v}} P ; \quad P_{\mathrm{a}}=n_{\mathrm{a}} P$,

$n_{\mathrm{v}}=\frac{x_{\mathrm{v}} / m_{\mathrm{v}}}{x_{\mathrm{v}} / m_{\mathrm{v}}+x_{\mathrm{a}} / m_{\mathrm{a}}} ; \quad n_{\mathrm{a}}=\frac{x_{\mathrm{a}} / m_{\mathrm{a}}}{x_{\mathrm{v}} / m_{\mathrm{v}}+x_{\mathrm{a}} / m_{\mathrm{a}}}$,

where $P_{\mathrm{v}}$ and $P_{\mathrm{a}}$ are, respectively, the partial pressures of the water vapour and of the air in the plume, $n_{\mathrm{v}}$ and $n_{\mathrm{a}}$ are the molar fractions of vapour and air in the gas phase $\left(n_{\mathrm{v}}+n_{\mathrm{a}}=\right.$ 1) and $m_{\mathrm{v}}=0.018 \mathrm{~kg} / \mathrm{mole}$ and $m_{\mathrm{a}}=0.029 \mathrm{~kg} / \mathrm{mole}$ are the molar weights of vapour and air. Following Woods (1993) and Woodhouse et al. (2013), we consider that, if the airwater mixture becomes saturated in water vapour, condensation or deposition occurs and the plume remains just saturated. This assumption implies that the partial pressure of water vapour $P_{\mathrm{v}}$ equals the saturation pressure of vapour over liquid $\left(e_{1}\right)$ or over ice $\left(e_{\mathrm{s}}\right)$ at the bulk temperature, and the saturation pressures over liquid and ice are given (in $\mathrm{hPa}$ ) by (Murphy and Koop, 2005)

$e_{1}=6.112 \exp \left(17.67 \frac{\hat{T}-273.16}{\hat{T}-29.65}\right)$

$\log e_{\mathrm{s}}=-9.097\left(\frac{273.16}{\hat{T}}-1\right)-3.566 \log \left(\frac{273.16}{\hat{T}}\right)$,

$+0.876\left(1-\frac{\hat{T}}{273.16}\right)+\log (6.1071)$.

Equation (9) holds for $\hat{T} \geq T_{f}$ and Eq. (10) is valid for $\hat{T} \leq$ $T_{f}$, where $T_{f}$ is the temperature of the triple point of the water (here set at $P_{f}=611.2 \mathrm{~Pa}, T_{f}=273.16 \mathrm{~K}$ ). Therefore, if $\hat{T}>T_{f}$ and $P_{\mathrm{v}}<e_{1}$, the plume is undersaturated and there is no water vapour condensation (i.e. $\hat{x}_{\mathrm{v}}=\hat{x}_{\mathrm{w}}$ and $\hat{x}_{1}=\hat{x}_{\mathrm{s}}=$ $0)$. In contrast, if $P_{\mathrm{v}} \geq e_{1}$, the vapour in excess is immediately converted into liquid and

$\left(P-e_{1}\right) n_{\mathrm{v}}=e_{1} n_{\mathrm{a}}$

$\hat{x}_{\mathrm{s}}=0$

$\hat{x}_{1}=\hat{x}_{w}-\hat{x}_{\mathrm{v}}$.

The vapour and air mass fractions $x_{\mathrm{v}}$ and $x_{\mathrm{a}}$ are evaluated by combining Eq. (11) and (8b). On the other hand, if $\hat{T} \leq$ $T_{f}$ and $P_{\mathrm{v}}<e_{\mathrm{s}}$ the plume is undersaturated and there is no water vapour deposition. In contrast, if $P_{\mathrm{v}} \geq e_{\mathrm{s}}$, the vapour in excess is immediately converted into ice and

$\left(P-e_{\mathrm{S}}\right) n_{\mathrm{v}}=e_{\mathrm{s}} n_{\mathrm{a}}$

$\hat{x}_{1}=0$

$\hat{x}_{\mathrm{s}}=\hat{x}_{w}-\hat{x}_{\mathrm{v}}$.

Again, the vapour and air mass fractions $x_{\mathrm{v}}$ and $x_{\mathrm{a}}$ are evaluated by combining Eq. (12) and (8b). 
For the particle re-entrainment parameter $f$ we adopt the fit proposed by Ernst et al. (1996) using data for plumes not affected by wind:

$f=0.43\left(1+\left[\frac{0.78 u_{\mathrm{s}} P_{o}^{1 / 4}}{F_{o}^{1 / 2}}\right]^{6}\right)^{-1}$,

where $P_{o}=r_{o}^{2} \hat{u}_{o}^{2}$ and $F_{o}=r_{o}^{2} \hat{u}_{o} \hat{H}_{o}$ are the specific momentum and thermal fluxes at the vent $(s=0)$, and $\hat{H}_{o}$ is the enthalpy per unit mass of the mixture at the vent. This expression may overestimate re-entrainment for bent over plumes (Bursik, 2001). Finally, particle terminal settling velocity $u_{\mathrm{s} i}$ is parameterized as (Costa et al., 2006; Folch et al., 2009)

$u_{\mathrm{s} i}=\sqrt{\frac{4 g\left(\rho_{p i}-\hat{\rho}\right) d_{i}}{3 C_{\mathrm{d}} \hat{\rho}}}$,

where $d_{i}$ is the class particle diameter and $C_{\mathrm{d}}$ is a drag coefficient that depends on the Reynolds number $R e=d_{i} u_{\mathrm{s} i} \hat{\rho} / \hat{\mu}$. Several empirical fits exist for drag coefficients of spherical and non-spherical particles (e.g. Wilson and Huang, 1979; Arastoopour et al., 1982; Ganser, 1993; Dellino et al., 2005). In particular, Ganser (1993) gave a fit valid over a wide range of particle sizes and shapes covering the spectrum of volcanic particles considered in volcanic column models (lapilli and ash):

$$
\begin{aligned}
& C_{\mathrm{d}}=\frac{24}{\operatorname{Re} K_{1}}\left\{1+0.1118\left[\operatorname{Re}\left(K_{1} K_{2}\right)\right]^{0.6567}\right\} \\
& +\frac{0.4305 K_{2}}{1+\frac{3305}{\operatorname{Re} K_{1} K_{2}}}
\end{aligned}
$$

where $K_{1}$ and $K_{2}$ are two shape factors depending on particle sphericity, $\Psi$, and particle orientation. Given that the $C_{\mathrm{d}}$ depends on $\operatorname{Re}$ (i.e. on $u_{\mathrm{s}}$ ), Eq. 14 is solved iteratively using a bisection algorithm. Given a closure equation for the turbulent air entrainment velocity $u_{\mathrm{e}}$, and an aggregation model (defining the mass aggregation coefficients $A_{i}^{+}$ and $A_{i}^{-}$), Eq. (2j) to (2i) can be integrated along the plume axis from the inlet (volcanic vent) up to the neutral buoyancy level. Inflow (boundary) conditions are required at the vent $(s=0)$ for, e.g., total mass flow rate $\hat{M}_{o}$, bent over angle $\theta_{o}=90^{\circ}$, temperature $\hat{T}_{o}$, exit velocity $\hat{u}_{o}$, fraction of water $\hat{x}_{\text {wo }}$, null air mass flow rate $\hat{M}_{\mathrm{a}}=0$, vent coordinates $\left(x_{o}, y_{o}\right.$ and $z_{o}$ ), and mass flow rate for each particle class $\hat{M}_{i o}$. The latter is obtained from the total mass flow rate at inflow given the particle grain size distribution at the vent:

$\hat{M}_{i o}=f_{i o} \hat{M}_{o}\left(1-\hat{x}_{w o}\right)$,

where $f_{i o}$ is the mass fraction of class $i$ at the vent.

\subsection{Entrainment coefficients}

Turbulent entrainment of ambient air plays a key role on the dynamics of jets and buoyant plumes. In the basal region of volcanic columns, the rate of entrainment dictates whether the volcanic jet enters into a collapse regime by exhaustion of momentum before the mixture becomes positively buoyant, or whether it evolves into a convective regime reaching much higher altitudes. Early laboratory experiments (e.g. Hewett et al., 1971) already indicated that the velocity of entrainment of ambient air is proportional to velocity differences parallel and normal to the plume axis (see inset in Fig. 1):

$u_{\mathrm{e}}=\alpha_{\mathrm{s}}\left|\hat{u}-u_{\mathrm{a}} \cos \theta\right|+\alpha_{\mathrm{v}}\left|u_{\mathrm{a}} \sin \theta\right|$,

where $\alpha_{\mathrm{s}}$ and $\alpha_{\mathrm{v}}$ are dimensionless coefficients that control the entrainment along the stream-wise (shear) and crossflow (vortex) directions, respectively. Note that, in absence of wind (i.e. $u_{\mathrm{a}}=0$ ), the equation above reduces to $u_{\mathrm{e}}=\alpha_{\mathrm{s}} \hat{u}$ and the classical expression for entrainment velocity of Morton et al. (1956) is recovered. In contrast, under a wind field, both along-plume (proportional to the relative velocity differences parallel to the plume) and cross-flow (proportional to the wind normal component) contributions appear. However it is worth noting that Eq. (17) has not a solid theoretical justification and is used on an empirical basis. A vast literature exists regarding the experimental (e.g. Dellino et al., 2014) and numerical (e.g. Suzuki and Koyaguchi, 2009) determination of entrainment coefficients for jets and buoyant plumes. Based on these results, most 1-D integral plume models available in literature consider (i) same constant entrainment coefficients along the plume, (ii) piecewise constant values at the different regions or, (iii) piecewise constant values corrected by a factor $\sqrt{\hat{\rho} / \rho_{\mathrm{a}}}$ (Woods, 1993). Typical values for the entrainment coefficients derived from experiments are of the order of $\alpha_{\mathrm{s}} \approx 0.07-0.1$ for the jet region, $\alpha_{\mathrm{s}} \approx 0.1$ 0.17 for the buoyant region and $\alpha_{\mathrm{v}} \approx 0.3-1.0$ (e.g. Devenish, 2013). However, more recent experimental (Kaminski et al., 2005) and sensitivity analysis numerical studies (Charpentier and Espíndola, 2005) concluded that piecewise constant functions are valid only as a first approach, implying that 1-D integral models assuming constant entrainment coefficients do not always provide satisfactory results. This has also been corroborated by 3-D numerical simulations of volcanic plumes (Suzuki and Koyaguchi, 2013), which indicate that 1-D integral models overestimate the effects of wind on turbulent mixing efficiency (i.e. the value of $\alpha_{\mathrm{v}}$ ) and, consequently, underestimate plume heights under strong wind fields. For example, recent 3-D numerical simulation results for small-scale eruptions under strong wind fields suggest lower values of $\alpha_{\mathrm{V}}$, in the range 0.1-0.3 (Suzuki and Koyaguchi, 2015). For this reason, besides the option of constant entrainment coefficients, FPLUME allows for considering also a parameterization of $\alpha_{\mathrm{S}}$ and $\alpha_{\mathrm{v}}$ based on the local Richardson number. In particular, we use the empirical parameterization of Kaminski et al. (2005) and Carazzo et al. (2006, 2008a, b) that describes $\alpha_{\mathrm{s}}$ for jets and plumes as a function of the local Richardson number as

$\alpha_{\mathrm{s}}=0.0675+\left(1-\frac{1}{A\left(z_{\mathrm{s}}\right)}\right) R i+\frac{r}{2} \frac{1}{A\left(z_{\mathrm{s}}\right)} \frac{d A}{d z}$, 
where $A\left(z_{\mathrm{s}}\right)$ is an entrainment function depending on the dimensionless length $z_{\mathrm{s}}=z / 2 r_{o}$ ( $r_{o}$ is the vent radius) and $R i=g\left(\rho_{\mathrm{a}}-\hat{\rho}\right) r / \rho_{\mathrm{a}} \hat{u}^{2}$ is the Richardson number. Beside the local Richardson number, the entrainment coefficient $\alpha_{\mathrm{s}}$ depends on plume orientation (e.g. Lee and Cheung, 1990; Bemporad, 1994), therefore we modify Eq. 18 as:

$\alpha_{\mathrm{s}}=0.0675+\left(1-\frac{1}{A\left(z_{\mathrm{s}}\right)}\right) R i \sin \theta+\frac{r}{2} \frac{1}{A\left(z_{\mathrm{s}}\right)} \frac{d A}{d z}$.

Moreover, in order to use a compact analytical expression and extend it to values of $z_{\mathrm{s}} \leq 10$ we fitted the experimental data of Carazzo et al. (2006, 2008b) considering the following empirical function:

$A\left(z_{\mathrm{s}}\right)=c_{o} \frac{\left(z_{\mathrm{s}}^{2}+c_{1}\right)}{\left(z_{\mathrm{s}}^{2}+c_{2}\right)}$

$\frac{1}{A\left(z_{\mathrm{s}}\right)} \frac{d A}{d z}=\frac{1}{2 r_{0}} \frac{2\left(c_{2}-c_{1}\right) z_{\mathrm{s}}}{\left(z_{\mathrm{s}}^{2}+c_{1}\right)\left(z_{\mathrm{s}}^{2}+c_{2}\right)}$

and in order to extrapolate to low $z_{\mathrm{s}}$ we multiply $A\left(z_{\mathrm{s}}\right)$ for the following function $h\left(z_{\mathrm{s}}\right)$ that affects the behaviour only for small values of $z_{\mathrm{s}}$ :

$h\left(z_{\mathrm{s}}\right)=\frac{1}{1-c_{4} \exp \left(-5\left(z_{\mathrm{s}} / 10-1\right)\right)}$,

where $c_{i}$ are dimensionless fitting constants. Best-fit results and entrainment functions resulting from fitting Eq. (20a)(20c) are shown in Table 3 and Fig. 2, respectively. However, the veracity of the empirical parameterization in Eq. (18) was not observed by Wang and Wing-Keung Law (2002) in their experiments nor has it been seen in Direct Numerical Simulation (DNS) or Large Eddy Simulations (LES) simulations of buoyant plumes (e.g. Craske et al., 2015). Finally, for the vortex entrainment coefficient $\alpha_{\mathrm{v}}$, we adopt a parameterization proposed by Tate (2002) based on a few laboratory experiments:

$\alpha_{\mathrm{v}}=0.34\left(\sqrt{2|R i|} \frac{\bar{u}_{\mathrm{a}}}{\hat{u}_{o}}\right)^{-0.125}$,

where $\hat{u}_{o}$ is the mixture velocity at the vent and $\bar{u}_{\mathrm{a}}$ is the average wind velocity. For illustrative purposes, Fig. 3 shows the entrainment coefficients $\alpha_{\mathrm{s}}$ and $\alpha_{\mathrm{v}}$ predicted by Eqs. (19) and (21) for weak and strong plume cases under a prescribed wind profile. It is important stressing that air entrainment rates play a first-order role on eruptive plume dynamics and a simple description in terms of entrainment coefficients, both assuming them as empirical constants or describing them like in Eq. (18), represents an over-simplification of the real physics characterizing the processes. A better quantification of entrainment rates is one of the current main challenges of the volcanological community (see Costa et al., 2015, and references therein).

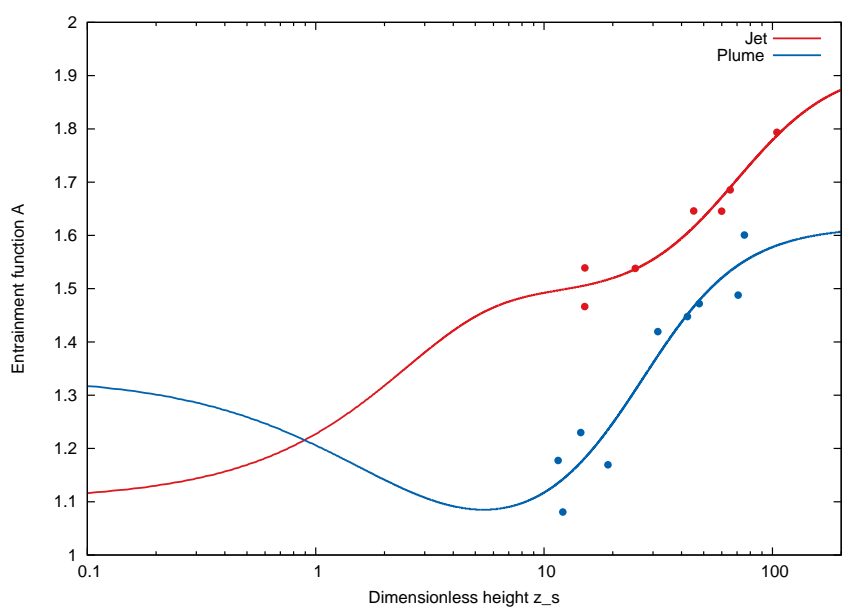

Figure 2. Entrainment functions $A\left(z_{\mathrm{S}}\right)$ for jets and plumes depending on the dimensionless height $z_{\mathrm{s}}=z / 2 r_{o}$. Functions have been obtained by fitting experimental data (points) from Carazzo et al. (2006) (for $z_{\mathrm{s}}>10$ ) and multiplying by a correction function (20c) to extend the functions to $z_{\mathrm{S}}<10$ verifying function continuity and convergence to values of $A=1.11$ for jets and $A=1.31$ for plumes when $z_{\mathrm{s}} \rightarrow 0$.

Table 3. Constants defining the entrainment functions for jets and plumes following the formulation introduced by Kaminski et al. (2005) (see Eq. 20a to 20c) obtained after fitting experimental data reported in Carazzo et al. (2006). For Kaminski-R we considered all data including that of Rouse et al. (1952), whereas for Kaminski-C, as suggested by Carazzo et al. (2006), data from Rouse et al. (1952) was excluded.

\begin{tabular}{l|cc|cc}
\hline & \multicolumn{2}{|c|}{ Kaminski-R } & \multicolumn{2}{c}{ Kaminski-C } \\
& jets & plumes & jets & plumes \\
\hline$c_{0}$ & 1.92 & 1.61717 & 1.92 & 1.55 \\
$c_{1}$ & 3737.26 & 478.374 & 3737.26 & 329.0 \\
$c_{2}$ & 4825.98 & 738.348 & 4825.98 & 504.5 \\
$c_{3}=2\left(c_{2}-c_{1}\right)$ & 2177.44 & 519.948 & 1883.81 & 351.0 \\
$c_{4}$ & 0.00235 & -0.00145 & 0.00235 & -0.00145 \\
\hline
\end{tabular}

\subsection{Modelling of the umbrella region}

The umbrella region is defined as the upper region of the plume, from about the NBL to the top of the column. This region can be dominated by fountaining processes of the eruptive mixture that reaches the top of the column, dissipating the excess of momentum at the NBL, and then collapsing as a gravity current (e.g. Woods and Kienle, 1994; Costa et al., 2013). The 1-D BPT should not be extended to this region because it assumes that the mixture still entrains air with the same mechanisms as below NBL and, moreover, predicts that the radius goes to infinity towards the top of the column. For these reasons, we describe the umbrella region adopting a simple semi-empirical approximation.

In the umbrella region (from the NBL to the top of the column), we neglect air entrainment and assume that the mix- 
ture is homogeneous, i.e. the content of air, water vapour, liquid water, ice and total mass of particles do not vary with $z$. Pressure $P(z)$ is considered equal to the atmospheric pressure $P_{\mathrm{a}}(z)$ evaluated at the same level, whereas temperature decreases with $z$ due to the adiabatic cooling:

$P(z)=P_{\mathrm{a}}(z)$ and $\frac{d T}{d P}=\frac{1}{\hat{c} \hat{\rho}}$.

As a consequence, the density of the mixture varies accordingly. The total height of the volcanic plume $H_{t}$, above the vent, is approximated as (e.g. Sparks, 1986)

$H_{t}=c_{H}\left(H_{\mathrm{b}}+8 r_{o}\right)$,

where $c_{H}$ is a dimensionless parameter (typically $c_{H}=$ 1.32 ), $H_{\mathrm{b}}$ is the height of the neutral buoyancy level (above the vent) and $r_{o}$ the radius at the vent. Between $H_{\mathrm{b}}$ and $H_{t}$, the coordinates $x$ and $y$ of the position of the plume centre and the plume radius $r$ are parameterized as a function of the elevation $z$, with $H_{\mathrm{b}} \leq z \leq H_{t}$. The position of the plume centre is assumed to vary linearly with the same slope at the NBL, whereas the effective plume radius is assumed to decrease as a Gaussian function:

$x=x_{\mathrm{b}}+\left.\left(z-H_{\mathrm{b}}\right) \frac{d x}{d z}\right|_{z=z_{\mathrm{b}}}$,

$y=y_{\mathrm{b}}+\left.\left(z-H_{\mathrm{b}}\right) \frac{d y}{d z}\right|_{z=z_{\mathrm{b}}}$,

$r=r_{\mathrm{b}} e^{-\left(z-H_{\mathrm{b}}\right)^{2} / 2 \sigma_{H}^{2}}$,

where $x_{b}, y_{b}, r_{b}$ are, respectively, the coordinates $x$ and $y$ of the centre of the plume and the plume radius at the NBL, and $\sigma_{H}=H_{t}-H_{\mathrm{b}}$.

Finally, assuming that the kinetic energy of the mixture is converted to potential energy, the vertical velocity is approximated to decrease as the square root of the distance from the NBL:

$u_{z}=u_{z \mathrm{~b}} \sqrt{\frac{H_{t}-z}{H_{t}-H_{\mathrm{b}}}}$,

where $u_{z \mathrm{~b}}$ is the vertical velocity of the plume at the NBL. Although the proposed empirical parameterization of the region above the NBL is qualitatively consistent with the trends predicted by 3-D numerical models (Costa et al., 2015), a more rigorous description requires further research.

\section{Plume wet aggregation model}

Particle aggregation can occur inside the column or in the ash cloud during subsequent atmospheric dispersion (e.g. Carey and Sigurdsson, 1982; Durant et al., 2009), thereby affecting the sedimentation dynamics and deposition of volcanic ash. Our model explicitly accounts for aggregation in the plume by adding source $\left(A_{i}^{+}\right)$and sink $\left(A_{i}^{-}\right)$terms for aggregates and aggregated particles in their respective particle mass balance Eqs. $(2 \mathrm{~g})$ and by modifying the settling velocity of aggregates. Given the complexity of aggregation phenomena, not yet fully understood, we consider only the occurrence of wet aggregation and neglect dry aggregation mechanisms driven by electrostatic forces or disaggregation processes resulting from particle collisions that can break and decompose aggregates. Costa et al. (2010) and Folch et al. (2010) proposed a simplified wet aggregation model in which particles aggregate on a single effective aggregated class characterized by a diameter $d_{\mathrm{A}}$ (i.e. aggregation only involves particle classes having an effective diameter smaller than $d_{\mathrm{A}}$, typically in the range 100-300 $\mu \mathrm{m}$ ). Obviously the assumption that all particles aggregate into a single particle class is simplistic and considering a range of aggregating classes would be more realistic. However, there are no quantitative data available for such a calibration. Hence, considering this assumption it follows that

$A_{i}^{+}=\sum_{j=k+1}^{n} A_{j}^{-} \delta_{i k}$,

where $k$ is the (given) index of the aggregated class and the sum over $j$ spans all particle classes having diameters lower than $d_{\mathrm{A}}$. The mass of particles of class $i\left(d_{i}<d_{\mathrm{A}}\right)$ that aggregate per unit of time and length in a given plume cross section is

$A_{i}^{-}=\dot{n}_{i}\left(\rho_{p i} \frac{\pi}{6} d_{i}^{3}\right) \pi r^{2}$,

where $\dot{n}_{i}$ is the number of particles of class $i$ that aggregate per unit volume and time, estimated as

$\dot{n}_{i} \approx \frac{\dot{n}_{\text {tot }} N_{i}}{\sum N_{j}}$.

In the expression above, $N_{i}$ is the number of particles of diameter $d_{i}$ in an aggregate of diameter $d_{\mathrm{A}}$, and $\dot{n}_{\text {tot }}$ is the total particle decay per unit volume and time. Costa et al. (2010) considered that $N_{i}$ is given by a semi-empirical fractal relationship (e.g. Jullien and Botet, 1987; Frenklach, 2002; Xiong and Friedlander, 2001):

$N_{i}=k_{f}\left(\frac{d_{\mathrm{A}}}{d_{i}}\right)^{D_{f}}$,

where $k_{f}$ is a fractal pre-factor and $D_{f}$ is the fractal exponent. Costa et al. (2010) and Folch et al. (2010) assumed constant values for $k_{f}$ and $D_{f}$ that were calibrated by bestfitting tephra deposits from 18 May 1980 Mount St. Helens and 17-18 September 1992 Crater Peak eruptions. However, for the granulometric data from these deposits they used a cut-off considering only particles larger than about $10 \mu \mathrm{m}$, for which the gravitational aggregation kernel dominates. This poses a problem if one wants to extend the granulometric 
distribution to include micrometric and sub-micrometric particles, for which the Brownian kernel is the dominant one (it is known that Brownian particle-particle interaction has typical values of $D_{f} \approx 2$, with values ranging between 1.5 and 2.5, e.g. Xiong and Friedlander, 2001). Actually, preliminary model tests involving micrometric and sub-micrometric particle classes considering constant values for $D_{f}$ and $k_{f}$ have revealed a strong dependency of results (fraction of aggregated mass) on both granulometric cut-off and bin width (particle grain size discretization). In order to overcome this problem, we assume a size-dependent fractal exponent as

$D_{f}(d)=D_{\text {fo }}-\frac{a\left(D_{\text {fo }}-D_{\min }\right)}{1+\exp \left(\left(d-d_{\mu}\right) / d_{\mu}\right)}$,

where $D_{f o} \leq 3, D_{\min }=1.6, d_{\mu} \approx 2 \mu \mathrm{m}$ and $a=1.36788$. The values of $D_{\min }$ and $d_{\mu}$ represent, respectively, the minimum value of $D_{f}$ relevant for sub-micrometric particles and the scale below which the Brownian aggregation kernel becomes dominant. For the fractal pre-factor $k_{f}$ we adopt the expression of Gmachowski (2002):

$k_{f}=\left[\sqrt{1.56-\left(1.728-\frac{D_{f}}{2}\right)^{2}}-0.228\right]^{D_{f}}\left(\frac{2+D_{f}}{D_{f}}\right)^{D_{f} / 2}$.

Figure 4 shows the values of $D_{f}(d)$ and $k_{f}(d)$ predicted by Eqs. (32) and (33) for a range of $D_{f o}$. We have performed different tests to verify that, in this way, the results of the aggregation model become much more robust independently of the distribution cut-off $\left(\Phi_{\min }=8,10,12\right)$ and bin width $(\Delta \Phi=1,0.5,0.25)$, with maximum differences in the aggregated mass laying always below $10 \%$.

The total particle decay per unit volume and time $\dot{n}_{\text {tot }}$ is given by

$\dot{n}_{\text {tot }}=\hat{f} \alpha_{\mathrm{m}}\left(A_{\mathrm{B}} n_{\mathrm{tot}}^{2}+A_{\mathrm{TI}} \phi^{4 / D_{f}} n_{\text {tot }}^{2-4 / D_{f}}\right.$

$\left.+A_{S} \phi^{3 / D_{f}} n_{\text {tot }}^{2-3 / D_{f}}+A_{\mathrm{DS}} \phi^{4 / D_{f}} n_{\text {tot }}^{2-4 / D_{f}}\right)$,

where $\alpha_{\mathrm{m}}$ is a mean (class-averaged) sticking efficiency, $\phi$ is the solid volume fraction, $n_{\text {tot }}$ is the total number of particles per unit of volume that can potentially aggregate and $\hat{f}$ is a correction factor that accounts for conversion from Gaussian to top-hat formalism (see Appendix A for details). The expression above comes from integrating the collection kernel over all particle sizes, and involves the product of the (averaged) sticking efficiency times the collision frequency function accounting for Brownian motion $\left(A_{\mathrm{B}}\right)$, collision due to turbulence as a result of inertial effects $\left(A_{\mathrm{TI}}\right)$, laminar and turbulent fluid shear $\left(A_{\mathrm{S}}\right)$, and differential sedimentation $\left(A_{\mathrm{DS}}\right)$. The term $A_{\mathrm{B}}$ derives from the Brownian collision kernel $\beta_{B, i j}$ (Costa et al., 2010):

$\beta_{B, i j}=\frac{2 k_{\mathrm{b}} \hat{T}}{3 \hat{\mu}} \frac{\left(d_{i}+d_{j}\right)^{2}}{d_{j} d_{j}}$,
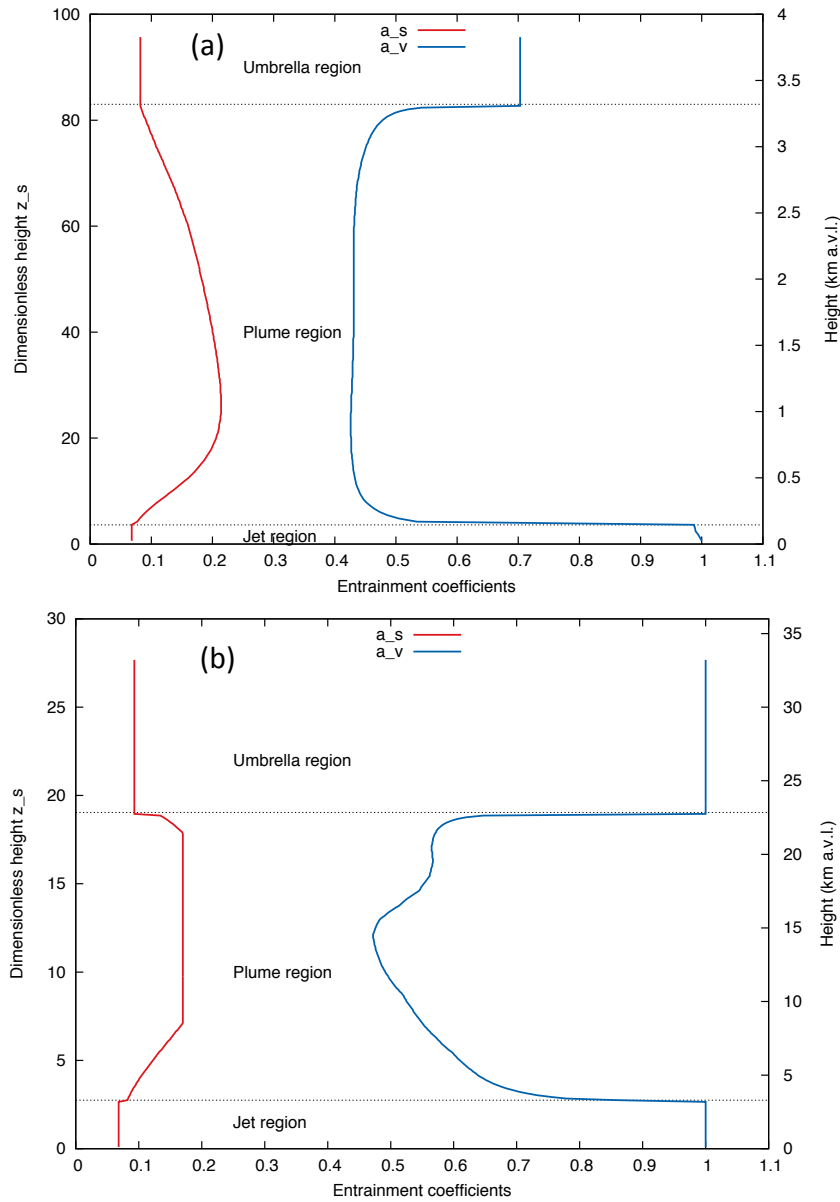

Figure 3. Entrainment coefficients $\alpha_{\mathrm{s}}$ (red) and $\alpha_{\mathrm{V}}$ (blue) versus height for weak (a) and strong (b) plumes under a wind profile. The vertical dashed lines indicate the transition between the different eruptive column regions. Weak plume simulation with: $\hat{M}_{o}=$ $1.5 \times 10^{6} \mathrm{kgs}^{-1}, \hat{u}_{o}=135 \mathrm{~ms}^{-1}, \hat{T}_{o}=1273 \mathrm{~K}, \hat{x}_{w o}=0.03$. Strong plume simulation with: $\hat{M}_{o}=1.5 \times 10^{9} \mathrm{~kg} \mathrm{~s}^{-1}, \hat{u}_{o}=300 \mathrm{~ms}^{-1}$, $\hat{T}_{o}=1153 \mathrm{~K}, \hat{x}_{w o}=0.05$.

where $k_{\mathrm{b}}$ is the Boltzmann constant and $\hat{\mu}$ is the mixture dynamic viscosity ( $\approx$ air viscosity at the bulk temperature $\hat{T}$ ). The term $A_{\mathrm{TI}}$ derives from the collision kernel due to turbulence as result of inertial effects $\beta_{\mathrm{TI}, i j}$ (e.g. Pruppacher and Klett, 1996; Jacobson, 2005):

$\beta_{\mathrm{TI}, i j}=\frac{\epsilon^{3 / 4}}{g \hat{v}^{1 / 4}} \frac{\pi}{4}\left(d_{i}+d_{j}\right)^{2}\left|u_{s j}-u_{\mathrm{s} i}\right|$,

where $\hat{v}$ is the mixture kinematic viscosity and $\epsilon$ is the dissipation rate of turbulent kinetic energy, computed assuming the Smagorinsky-Lilly model:

$\epsilon=2 \sqrt{2} k_{\mathrm{s}}^{2} \frac{\hat{u}^{3}}{r}$,

where $k_{\mathrm{s}} \approx 0.1-0.2$ is the constant of Smagorinsky. The term $A_{\mathrm{S}}$ derives from the collision kernel due to laminar and 
turbulent fluid shear $\beta_{S, i j}$ (Costa et al., 2010):

$\beta_{S, i j}=\frac{\Gamma_{S}}{6}\left(d_{i}+d_{j}\right)^{3}$,

where $\Gamma_{S}$ is the fluid shear, computed as

$\Gamma_{S}=\max \left(\left|\frac{d \hat{u}}{d r}\right|,\left(\frac{\epsilon}{v}\right)^{1 / 2}\right)$.

Finally, the term $A_{\mathrm{DS}}$ derives from the differential sedimentation collision kernel $\beta_{D S, i j}$ (e.g. Costa et al., 2010):

$\beta_{D S, i j}=\frac{\pi}{4}\left(d_{i}+d_{j}\right)^{2}\left|u_{\mathrm{si}}-u_{s j}\right|$,

where $u_{\mathrm{s} i}$ denotes the settling velocity of particle class $i$. Note that, with respect to the original formulation of Costa et al. (2010), using the same approach and approximation, we have included the additional term $A_{\mathrm{TI}}$ due to the turbulent inertial kernel that, thanks to the similarity between Eqs. (40) and (36), can be easily derived. Once these kernels are integrated, expressions for the terms in Eq. (34) yield

$A_{\mathrm{B}}=-\frac{4 k_{\mathrm{b}} \hat{T}}{3 \hat{\mu}}$

$A_{S}=-\frac{2}{3} \Gamma_{S} \xi^{3}$,

$A_{\mathrm{DS}}=-\frac{\pi\left(\rho_{\mathrm{p}}-\hat{\rho}\right) g \xi^{4}}{48 \hat{\mu}}$,

$A_{\mathrm{TI}}=1.82 \frac{\epsilon^{3 / 4}}{g v^{1 / 4}} A_{\mathrm{DS}}$

where $\xi=d_{j} v_{j}^{-1 / D_{f}}$ is the diameter to volume fractal relationship and $v_{j}$ is the particle volume. Note that for spherical particles in the Euclidean space $\left(D_{f}=3\right) v_{j}=\pi d_{j}^{3} / 6$ and $\xi=(6 / \pi)^{1 / 3}$.

The total number of particles per unit of volume available for aggregation is related to particle class mass concentration at each section of the plume $\hat{C}_{j}$ and can be estimated as (see Appendix B)

$n_{\text {tot }}=\frac{1}{3 \log 2} \sum_{j}\left(\frac{6 \hat{C}_{j}}{\pi \Delta \Phi_{j} \rho_{p j}}\right)\left[\frac{1}{d_{a j}^{3}}-\frac{1}{d_{b j}^{3}}\right]$,

where $d_{a j}$ and $d_{b j}$ are the particle diameters of the limits of the interval $j$ and

$\hat{C}_{j}=\hat{\rho} \frac{\hat{M}_{j}}{\hat{M}}$.
Finally, the class-averaged sticking efficiency $\alpha_{\mathrm{m}}$ appearing in Eq. (34) is computed as

$\alpha_{\mathrm{m}}=\frac{\sum_{i} \sum_{j} f_{i} f_{j} \alpha_{i j}}{\sum_{i} \sum_{j} f_{i} f_{j}}$

where $f_{k}$ is the particle class mass fraction, and $\alpha_{i j}$ is the sticking efficiency between the classes $i$ and $j$. In presence of a pure ice phase we assume that ash particles stick as ice particles $\left(\alpha_{\mathrm{m}}=0.09\right)$. In contrast, in presence of a liquid phase, the aggregation model considers

$\alpha_{i j}=\frac{1}{1+\left(S t_{i j} / S t_{\mathrm{cr}}\right)^{q}}$,

where $S t_{\mathrm{cr}}=1.3$ is the critical Stokes number, $q=0.8$ is a constant, and $S t_{i j}$ is the Stokes number based on the binder liquid (water) viscosity:

$S t_{i j}=\frac{8 \hat{\rho}}{9 \mu_{1}} \frac{d_{i} d_{j}}{d_{i}+d_{j}}\left|u_{i}-u_{j}\right|$,

where

$\left|u_{i}-u_{j}\right|=\left|u_{\mathrm{s} i}-u_{s j}\right|+\frac{8 k_{\mathrm{b}} \hat{T}}{3 \hat{\mu} \pi d_{i} d_{j}}+\frac{2 \Gamma_{\mathrm{s}}\left(d_{i}+d_{j}\right)}{3 \pi}$.

Obviously, our aggregation model requires the presence of water either in liquid or solid phases, i.e. aggregation will only occur in those regions of the plume where water vapour (of magmatic origin or entrained by moist air) meets condensation/deposition conditions (Costa et al., 2010; Folch et al., 2010). This depends on complex relationships between plume dynamics and ambient conditions. For highintensity (strong) plumes having high values of $\hat{M}$, the condition $P_{\mathrm{v}} \geq e_{1}$ when $\hat{T}>T_{f}$ is rarely met, implying no formation of a liquid water window within the plume. Aggregation occurs in this case only at the upper parts of the column, under the presence of ice. In contrast, lower-intensity (weak) plumes having lower values of $\hat{M}$ can form a liquid water window if the term $M_{\mathrm{a}}$ dominates in Eq. (8a). However, this also depends on a complex balance between air entrainment efficiency, ambient moisture, plume temperature, height level, cooling rate and ambient conditions. Aggregation by liquid water is much favoured under moist environments and by efficient air entrainment. Note that, keeping all eruptive parameters constant, the occurrence (or not) of wet aggregation by liquid water can vary with time depending on fluctuations of the atmospheric moisture and wind intensity along the day.

\section{FPLUME-1.0}

We solve the model equations using FPLUME-1.0, a code written in FORTRAN90 that uses the lsode library (Hindmarsh, 1980), to solve the set of first-order ordinary differential equations. Model inputs are eruption start and duration (different successive eruption phases can be considered), 
vent coordinates $\left(x_{o}, y_{o}\right)$ and elevation $\left(z_{o}\right)$, conditions at the vent (exit velocity $\hat{u}_{o}$, magma temperature $\hat{T}_{o}$, magmatic water mass fraction $\hat{w}_{o}$, and total grain size distribution) and total column height $H_{t}$ or mass eruption rate $\hat{M}_{o}$. The code has two solving modes. If $\hat{M}_{o}$ is given, the code solves directly for $H_{t}$. On the contrary, if $H_{t}$ is given, the code solves iteratively for $\hat{M}$. Wind profiles can be furnished in different formats, including standard atmosphere, atmospheric soundings, and profiles extracted from meteorological re-analysis data sets. If the aggregation model is switched on, additional inputs are required including size and density of the aggregated class, aggregates settling velocity factor (to account for the decrease in settling velocity of aggregates due to increase in porosity), and fractal exponent for coarse particles $D_{f o}$. The rest of the parameters (specific heats, the value of the constant $\chi$ for particle fallout probability, parameterization of the entrainment coefficients, etc.) have assigned default values but can be modified by the user using a configure file.

Model outputs include a text file with the results for each eruption phase giving values of all computed variables (e.g. $\hat{u}, \hat{T}, \hat{\rho})$ at different heights, and a file giving the mass flow rate of each particle class that falls from the column at different heights (cross sections). This file provides the phasedependent source term, and hence serves to couple FPLUME with atmospheric dispersion models. In case of wet aggregation, the effective granulometry predicted by the aggregation model is also provided. The solution of the aggregation model embedded in FPLUME-1.0 consists on the following steps:

1. At each section of the plume, determine the water vapour condensation or deposition conditions depending on $\hat{T}$ and $P_{\mathrm{v}}$ using Eqs. (11) or (12), respectively.

2. In case of saturation or deposition, compute the classaveraged sticking efficiency $\alpha_{\mathrm{m}}$ for liquid water or ice using Eq. (44).

3. Estimate the total number of particles per unit of volume available for aggregation $n_{\text {tot }}$ depending on $\hat{C}_{j}$ using Eq. (42).

4. Compute the integrated aggregation kernels using Eq. (41a) to (41d).

5. Compute the total particle decay per unit volume and time $\dot{n}_{\text {tot }}$ using Eq. (34) depending also on the solid volume fraction.

6. Compute the number of particles of diameter $d_{i}$ in an aggregate of given diameter $d_{\mathrm{A}}$ using Eq. (31) assuming size-dependent fractal exponent $D_{f}$ and pre-factor $k_{f}$.

7. Compute class particle decay $\dot{n}_{i}$ using Eq. (30).

8. Finally, compute the mass sink term for each aggregating class $A_{i}^{-}$using Eq. (29) and the mass source term $A_{i}^{+}$for the aggregated class using Eq. (28) to introduce these terms in the particle class mass balance equations, Eq. (2g).

\section{Test cases}

As we mentioned above, here we apply FPLUME to two eruptions relatively well characterized by previous studies. In particular we consider the strong plume formed during 4 April 1982 by El Chichón 1982 eruption (e.g. Sigurdsson et al., 1984; Bonasia et al., 2012) and the weak plume formed during the 6 May 2010 Eyjafjallajökull eruption (e.g. Bonadonna et al., 2011; Folch, 2012).

\subsection{Phase-B El Chichón 1982 eruption}

El Chichón volcano reawakened in 1982 with three significant Plinian episodes occurring during March 29th (phase A) and April 4th (phases B and C). Here we focus on the second major event, starting at 01:35 UTC on April 4th and lasting nearly $4.5 \mathrm{~h}$ (Sigurdsson et al., 1984). Bonasia et al. (2012) used analytical (HAZMAP) and numerical (FALL3D) tephra transport models to reconstruct ground deposit observations for the three main eruption fallout units. Deposit bestfit inversion results for phase-B suggested column heights between 28 and $32 \mathrm{~km}$ (above vent level, a.v.l.) and a total erupted mass ranging between $2.2 \times 10^{12}$ and $3.7 \times 10^{12} \mathrm{~kg}$. Considering a duration of $4.5 \mathrm{~h}$, the resulting averaged mass eruption rates are between $1 \times 10^{8}$ and $2.3 \times 10^{8} \mathrm{~kg} / \mathrm{s}$. TGSD of phases B and C were estimated by Rose and Durant (2009) weighting by mass, by isopach volume and using the Voronoi method. Bonasia et al. (2012) found that the reconstruction of the deposits is reasonably achieved taking into account the empirical Cornell aggregation parameterization (Cornell et al., 1983). In this simplistic approach, $50 \%$ of the 63$44 \mu \mathrm{m}$ ash, $75 \%$ of the $44-31 \mu \mathrm{m}$ ash and $100 \%$ of the less than $31 \mu \mathrm{m}$ ash are assumed to aggregate as particles with a diameter of $200 \mu \mathrm{m}$ and density of $200 \mathrm{~kg} \mathrm{~m}^{-3}$. Note that here, as in previous studies (Folch et al., 2010), we use a modified version of Cornell et al. (1983) parameterization that assumes that $90 \%$ and not $100 \%$ of the particles smaller than $31 \mu \mathrm{m}$ fall as aggregates.

We use this test case to verify whether FPLUME can reproduce results from these previous studies and the results of our aggregation model are, in this case, consistent with those of Cornell et al. (1983) parameterization. Input values for FPLUME are summarized in Table 4. We used the TGSD of Rose and Durant (2009) with 17 particle classes ranging from $64 \mathrm{~mm}(\Phi=-6)$ to $1 \mu \mathrm{m}(\Phi=10)$. The wind profile has been obtained from the University of Wyoming soundings database (weather.uwyo.edu/upperair/sounding.html) for 4 April 1982 at 00:00 UTC at the station number 76644 (lon $=-89.65$, lat $=20.97)$. Figure 5 shows the wind profile and the FPLUME results for bulk velocity and plume radius. The model predicts a total plume height of $28 \mathrm{~km}$ 
Table 4. Input values for the El Chichón Phase-B simulation. Values for specific heat of water vapour, liquid water, ice, pyroclasts and air at constant pressure are assigned to defaults of 1900, 4200, 2000, 1600 and $1000 \mathrm{Jkg}^{-1} \mathrm{~K}^{-1}$.

\begin{tabular}{lccl}
\hline Parameter & Symbol & Units & Value \\
\hline Phase start & & $\mathrm{h}$ & $01: 35 \mathrm{UTC}$ \\
Phase end & & $\mathrm{h}$ & $06: 00 \mathrm{UTC}$ \\
Exit velocity & $\hat{u}_{o}$ & $\mathrm{~ms}^{-1}$ & 350 \\
Exit temperature & $\hat{T}_{o}$ & $\mathrm{~K}$ & 1123 \\
Water mass fraction & $\hat{w}_{o}$ & - & $4 \%$ \\
Diameter aggregates & $d_{\mathrm{A}}$ & $\mu \mathrm{m}^{-3}$ & 250 \\
Density aggregates & $\hat{\rho}_{A}$ & $\mathrm{~kg} \mathrm{~m}^{-3}$ & 200 \\
Probability of particle fallout & $\chi$ & - & 0.23 \\
Shear entrainment coefficient & $\alpha_{\mathrm{S}}$ & - & Eq. (19) \\
Vortex entrainment coefficient & $\alpha_{\mathrm{V}}$ & - & Eq. (21) \\
\hline
\end{tabular}

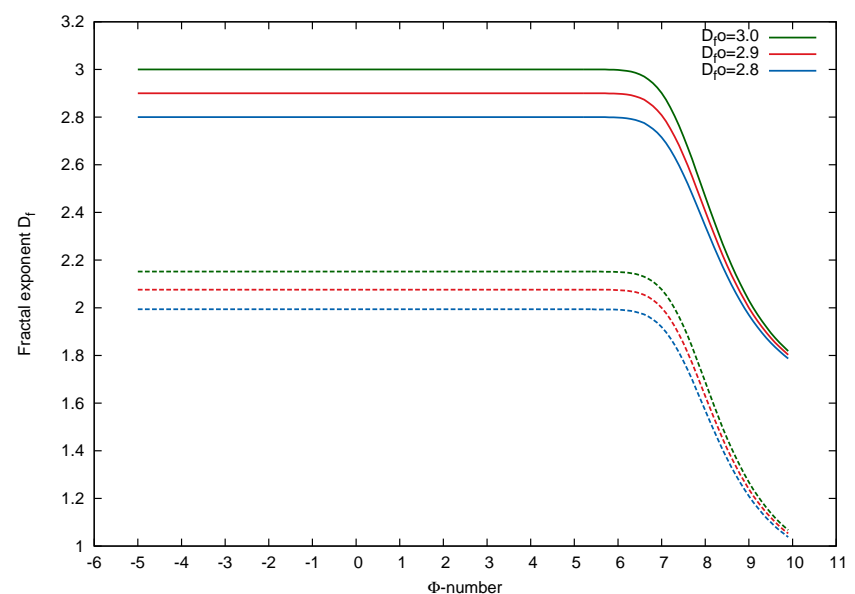

Figure 4. Dependency of fractal exponent $D_{f}$ (continuous lines) and fractal pre-factor $k_{f}$ (dashed lines) on particle size expressed in $\Phi$ units according to Eq. (32) and (33) for different values of $D_{f o}$. Note the progressive decay in $D_{f}$ starting at $\Phi=7(d \approx 10 \mu \mathrm{m})$ and leading to values of $D_{f}=1.6$ for $\Phi=9(d \approx 2 \mu \mathrm{m})$.

(a.s.1.), a mass eruption rate of $2.7 \times 10^{8} \mathrm{~kg} \mathrm{~s}^{-1}$ and a total erupted mass of $4.4 \times 10^{12} \mathrm{~kg}$. These values are consistent but slightly higher than those from previous studies (Bonasia et al., 2012). Regarding the aggregation model, we did several sensitivity runs to look into the impact of the fractal exponent $D_{f o}$ on the fraction of aggregates, ranging this parameter between 2.85 and 3.0 at 0.01 steps values (see Fig. 6). As anticipated in the original formulation (Costa et al., 2010; Folch et al., 2010), the results of the aggregation model are sensitive to this parameter. Values of $D_{f o}=2.96$ fit very well the total mass fraction of aggregates predicted by Cornell but not the fraction of the aggregating classes (Fig. 7b). In contrast, we find a more reasonable fit with $D_{f o}=2.92$, although in this case the relative differences for the total mass fraction of aggregates are of about $15 \%$, with our model under-predicting with respect to Cornell (Fig. 7a).
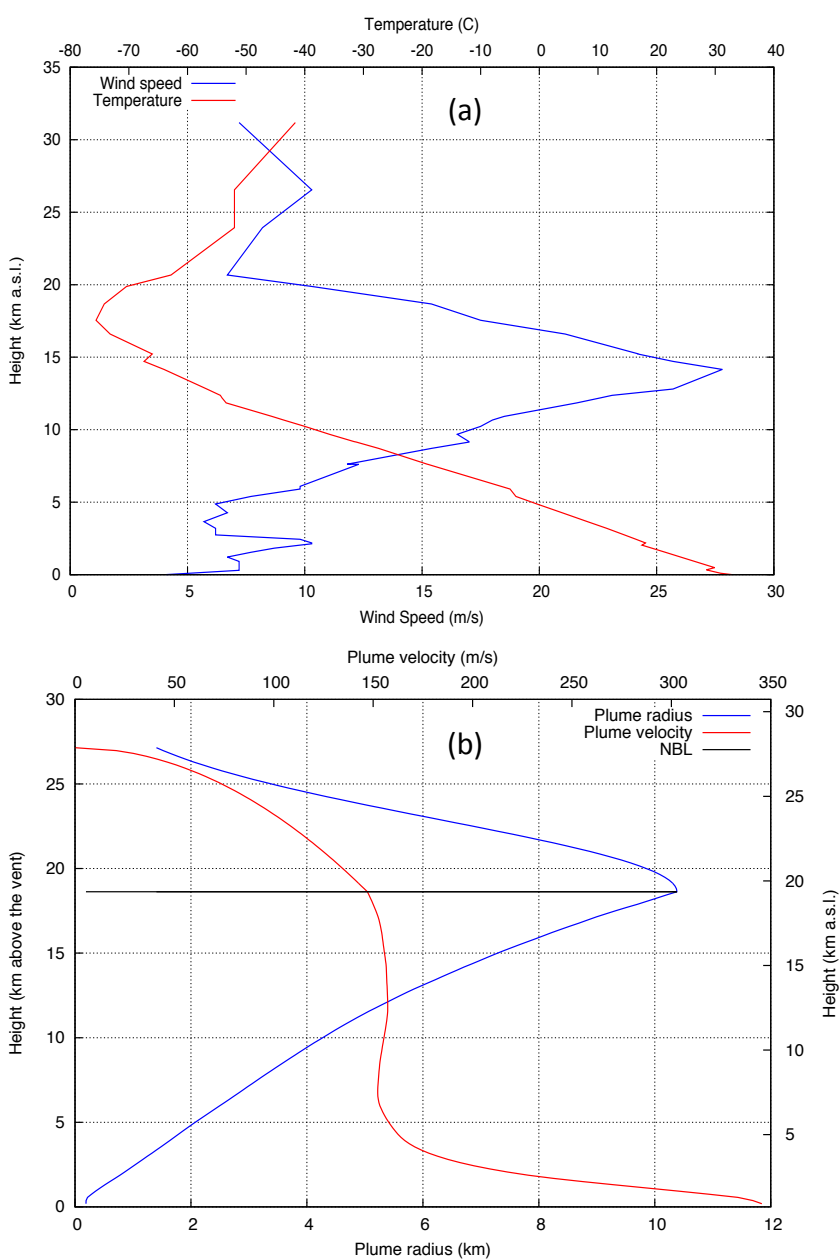

Figure 5. (a): wind and temperature atmospheric profiles during 4 April 1982 at 00:00 UTC from sounding. (b): FPLUME bulk velocity $\hat{u}$ and radius $r$ with height $z$. The black solid line indicates the height of the NBL determined by the model.

A clear advantage of a physical aggregation model of ash particles inside the eruption column, with respect to an empirical parameterization like Cornell et al. (1983), is that it allows for estimating the fraction of very fine ash that escapes to aggregation processes and is transported distally within the cloud. As we mentioned above, based on the features of the observed deposits, Cornell et al. (1983) proposed that 100\% of particles smaller than $31 \mu \mathrm{m}$ fall as aggregates, which is quite reasonable as most of fine ash falls prematurely. However assessing the small mass fraction of fine ash that escapes to aggregation processes is crucial for aviation risk mitigation and for comparing model simulations with satellite observations. For example, in the case of El Chichón 1982 eruption, for $D_{f o}=2.92$, the model predicts that $\approx 10 \%$ of fine ash between 20 and $2 \mu \mathrm{m}$ in diameter escapes to aggregation processes. This value is an order of magnitude larger than that estimated by Schneider et al. (1999) using Total Ozone Mapping Spectrometer (TOMS) and Advanced Very 


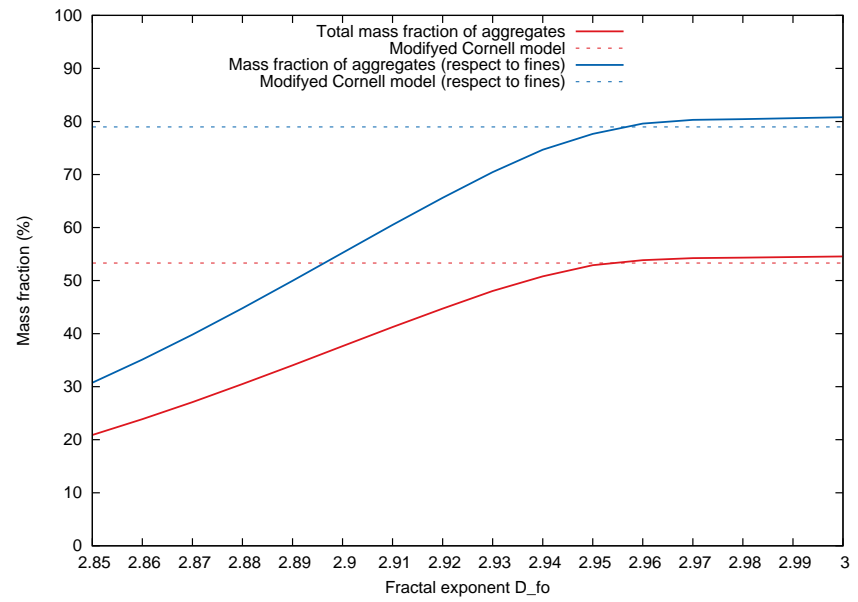

Figure 6. El Chichón 1982 phase-B simulation. Total mass fraction of aggregates (red line) and total mass fraction of aggregates with respect to fines (blue line), depending on the fractal exponent $D_{f o}$. The (constant) values predicted by the modified Cornell model are shown by dashed lines.

High Resolution Radiometer (AVHRR) data, but we need to consider that we do not account for dry aggregation that can be dominant for very fine particles.

\subsection{May 2010 Eyjafjallajökull eruption phase}

The infamous April-May 2010 Eyjafjallajökull eruption, that disrupted the European North Atlantic region airspace (e.g. Folch, 2012), was characterized by a very pulsating behaviour, resulting on nearly continuous production of weak plumes that oscillated on height between 2 and $10 \mathrm{~km}$ (a.s.l.) during the 39-day-long eruption (e.g. Gudmundsson et al., 2012). During 4-8 May, Bonadonna et al. (2011) performed in situ observations of tephra accumulation rates and PLUDIX Doppler radar measurements of settling velocities at different locations, which then used to determine erupted mass, mass eruption rates and grain size distributions. The authors estimated a TGSD representative of $30 \mathrm{~min}$ of eruption by combining ground-based grain-size observations (using a Voronoi tessellation technique) and ash mass retrievals (7-9 $\Phi$ particles) from MSG-SEVIRI satellite imagery for 6 May between 11:00 and 11:30 UTC. On the other hand, they also report the in situ observation of sedimentation of dry and wet aggregates falling as particle clusters and poorly structured and liquid accretionary pellets (AP1 and AP3 according to Brown et al. (2012) nomenclature). Bonadonna et al. (2011) did also grain-size analyses of collected aggregates using scanning electron microscope (SEM) images. The combination of all these data allowed them to determine how the original TGSD was modified by the formation of different types of aggregates (see Fig. 8). The total mass fraction of aggregates was estimated to be about $25 \%$ with aggregate sizes ranging between $1 \Phi(500 \mu \mathrm{m})$ and $4 \Phi(62.5 \mu \mathrm{m})$. These
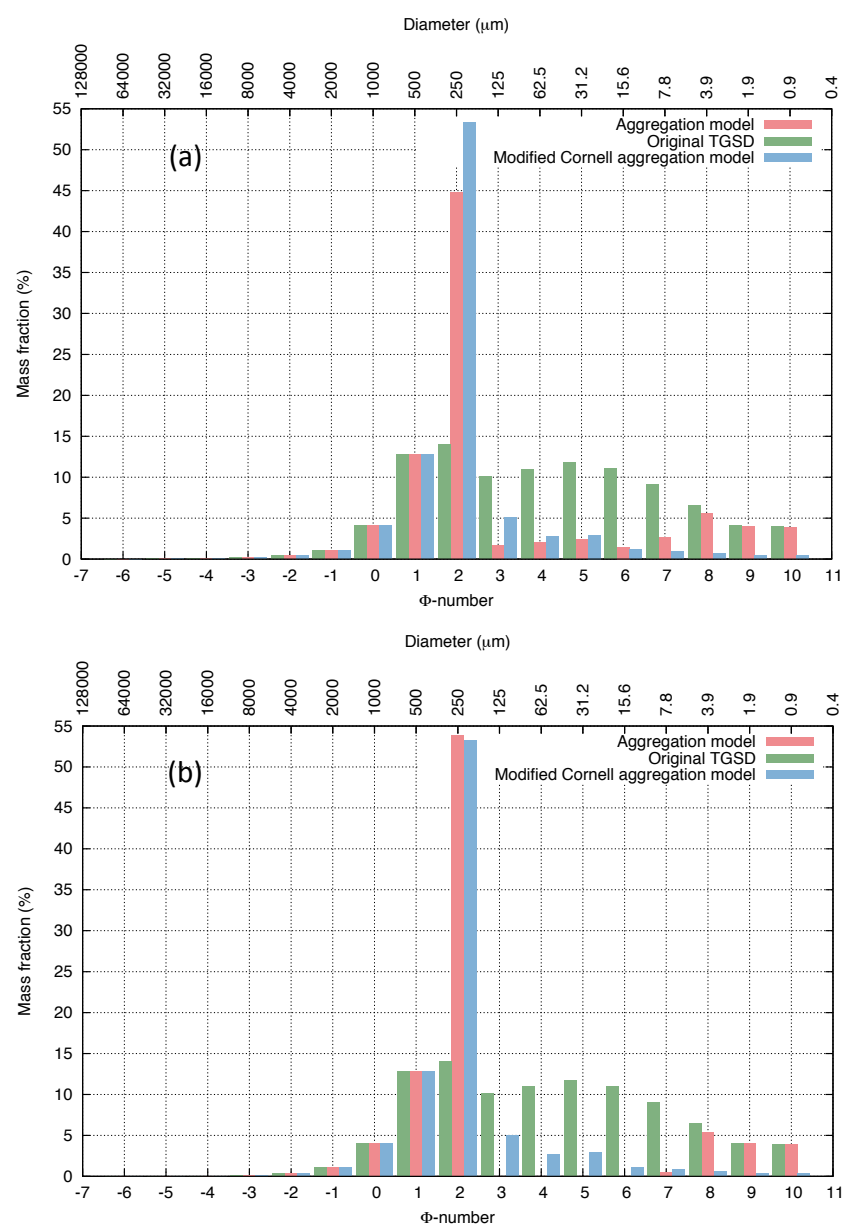

Figure 7. Results of the aggregation model in FPLUME for El Chichón 1982 phase-B simulation. Green bars show the original TGSD from Rose and Durant (2009) discretized in $17 \Phi$-classes. Blue bars show the results of the modified Cornell model. Finally, read bars give the results of our wet aggregation model considering a fractal exponent of $D_{f o}=2.92$ (a) and $D_{f o}=2.96$ (b).

results constitute a rare and valuable data set to test the aggregation model implemented in FPLUME. However, several challenges can be anticipated. First, our model assumes a single aggregated class and, as a consequence, we may expect to reproduce only the total mass fraction of aggregates, but not to match the resulting mass fraction distribution class by class. Second, the proportion of dry versus wet aggregates is unknown and, wet aggregation could have occurred within the plume but also by local rain showers that scavenged coarse particles (Bonadonna et al., 2011); moreover, the presence of meteoritic water in the plume (not considered here) could significantly enhance aggregation. For these reasons, we aim to capture the correct order of magnitude of total mass fraction of ash that went into aggregates.

Preliminary simulations using time-averaged plume heights of 3.5-4.5 km (a.v.l.) did not result in formation of aggregates because the model did not predict the existence 


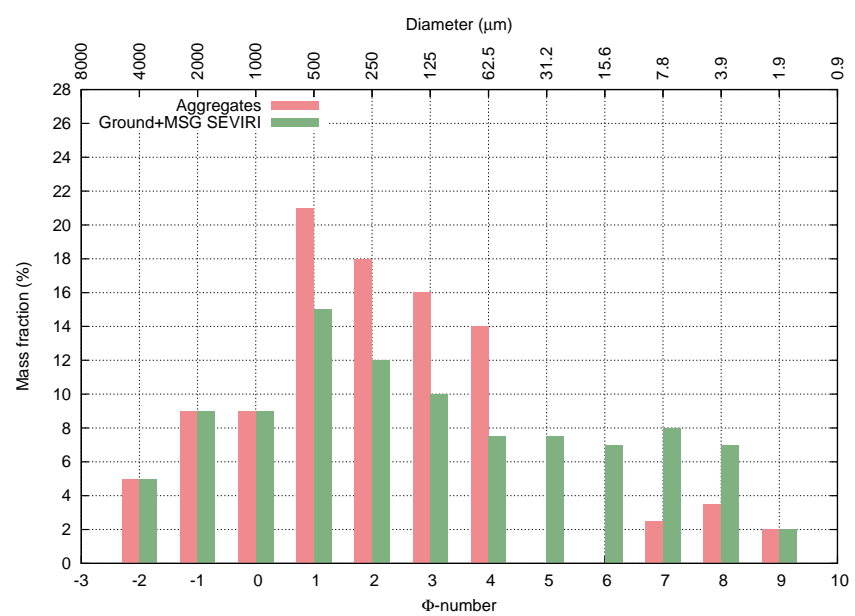

Figure 8. Original grain size distribution from ground data and MSG-SEVIRI retrievals (green) and distribution modified by aggregation (red). Results are for 6 May $30 \mathrm{~min}$ averaged. Figure reproduced from Bonadonna et al. (2011) (Fig.17d).

Table 5. FPLUME input values for the 6 May Eyjafjallajökull simulation. Values for specific heats of water vapour, liquid water, ice, pyroclasts and air at constant pressure are assigned to defaults of $1900,4200,2000,1600$ and $1000 \mathrm{Jkg}^{-1} \mathrm{~K}^{-1}$.

\begin{tabular}{lccl}
\hline Parameter & Symbol & Units & Value \\
\hline Phase start & & $\mathrm{h}$ & $06: 00 \mathrm{UTC}$ \\
Phase end & & $\mathrm{h}$ & $12: 00 \mathrm{UTC}$ \\
Exit velocity & $\hat{u}_{o}$ & $\mathrm{~ms}^{-1}$ & 150 \\
Exit temperature & $\hat{T}_{o}$ & $\mathrm{~K}$ & 1200 \\
Water mass fraction & $\hat{w}_{o}$ & - & $3 \%$ \\
Diameter aggregates & $d_{\mathrm{A}}$ & $\mu \mathrm{m}$ & 500 \\
Density aggregates & $\hat{\rho}_{A}$ & $\mathrm{~kg} \mathrm{~m}^{-3}$ & 200 \\
Probability of particle fallout & $\chi$ & - & 0.23 \\
Shear entrainment coefficient & $\alpha_{\mathrm{S}}$ & - & Eq. (19) \\
Vortex entrainment coefficient & $\alpha_{\mathrm{V}}$ & - & Eq. (21) \\
\hline
\end{tabular}

of a liquid water window nor the formation of ice. However, on short timescales these plume heights are very different from the daily (hourly) time-averaged values. In fact, Arason et al. (2011) determined a 5 min time series of the echo-top radar data of the eruption plume altitude and for 6 May they observed oscillations between 3.5 and $8.5 \mathrm{~km}$ (a.v.l). This is consistent with Gudmundsson et al. (2012), who for 6 May reported a median plume height of $4 \mathrm{~km}$ (a.v.l.) and a maximum elevation of around $8 \mathrm{~km}$ (a.v.l.). This may suggest that wet aggregates could have formed within the plume not continuously but during sporadic higher-intensity column pulses. In order to check this possibility, we performed a parametric study to compute the total mass fraction of wet aggregates as function of mass flow rate that controls the value of the column height.

Input values for FPLUME are summarized in Table 5. The wind profile (see Fig. 9) was extracted from the ERA-Interim re-analysis data set interpolating values at the vent coordi-
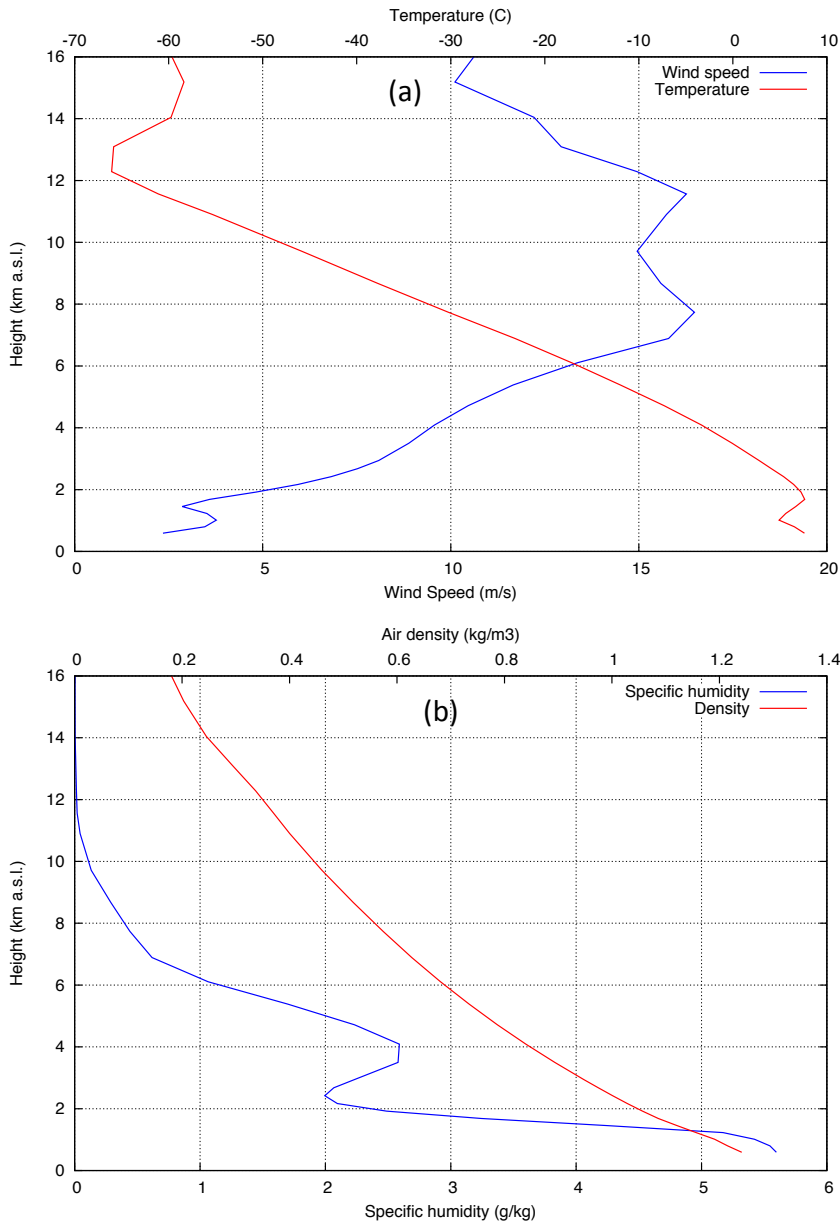

Figure 9. Atmospheric profiles extracted form ERA-Interim reanalysis data set at Eyjafjallajökull vent location for 6 May 2010 at 12:00 UTC. (a): wind and temperature profiles. (b): specific humidity and air density profiles.

nates. As shown in Fig. 10, $10 \%$ in mass of wet aggregates is predicted by our model for column heights ranging between 6 and $7 \mathrm{~km}$ (a.v.l.) and $20 \%$ for column heights from 7.2 to $8.3 \mathrm{~km}$ (a.v.l.). For the considered input parameters and ambient conditions (wind and moisture profile), we observed the formation of a window in the plume containing liquid water only for column heights above $5.3 \mathrm{~km}$ (a.v.l.). For illustrative purposes, Fig.11 shows the resulting grain size distribution for a column height of $6.5 \mathrm{~km}$ (a.v.l.) and two different values of the fractal exponent $D_{f}$. As anticipated, the model can predict the total mass fraction of aggregates, but an error $(<10 \%)$ exists for some particular classes. However, it should be kept in mind that mass fraction of aggregates is not controlled only by the eruptive column height but depends on several variables such as particle concentration (that is a function of the mass flow rate), presence of liquid water (that can form above a given level depending on the local meteorological conditions), etc. 


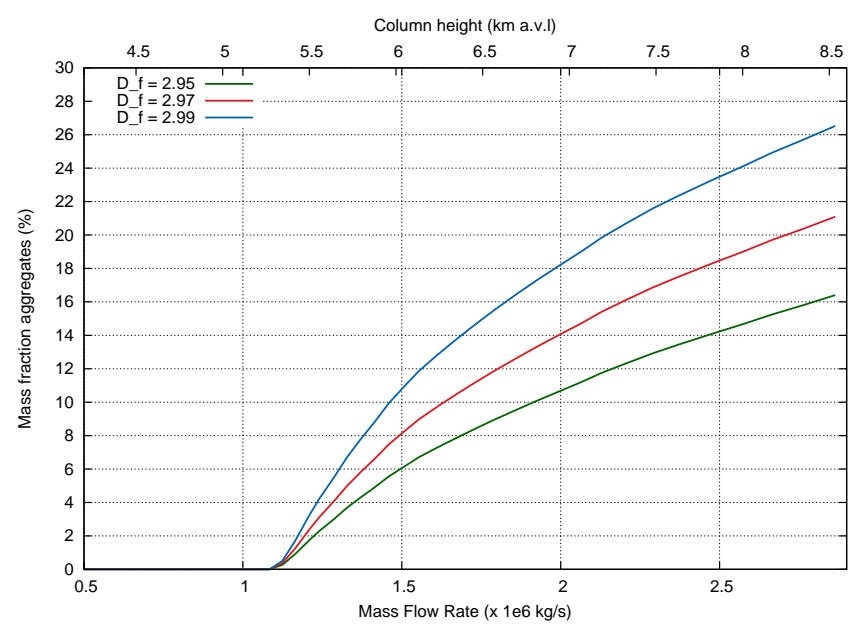

Figure 10. FPLUME aggregation model results for Eyjafjallajökull 6 May phase. Total mass fraction of aggregates (in \%) versus mass flow rate (in $\mathrm{kg} \mathrm{s}^{-1}$ ) and column height (in $\mathrm{km}$ a.v.l.) for different values of the fractal exponent $D_{f o}$ (in these simulations we used $c_{H}=1.1$ and the presence of meteoritic water in the plume was not considered). The model predicts a $10 \%$ in mass of wet aggregates for column heights between 6.0 and $7.0 \mathrm{~km}$ (a.v.1.). Input parameters were fixed as in Table 5 varying mass flow rate (column height).

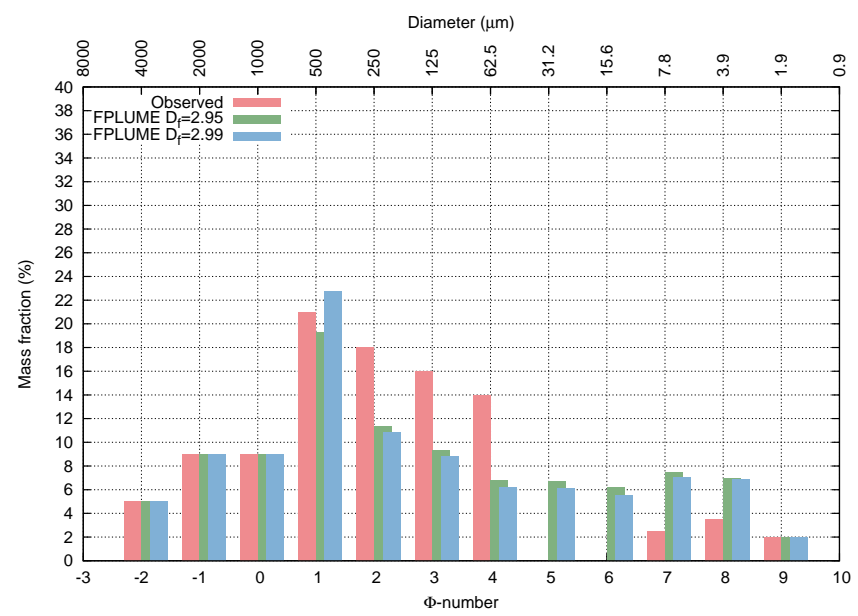

Figure 11. Grain size distribution predicted by the wet aggregation model for Eyjafjallajökull 6 May phase for a column height of $6.5 \mathrm{~km}$ (a.v.l.) for two different values of the fractal exponent $D_{f o}$ of 2.95 and 2.99. Observed data from Bonadonna et al. (2011).

\section{Conclusions}

We presented FPLUME, a 1-D cross-section-averaged volcanic plume model based on the BPT that accounts for plume bending by wind, entrainment of ambient moisture, effects of water phase changes, particle fallout and re-entrainment, a new parameterization for the air entrainment coefficients and an ash wet aggregation model based on Costa et al. (2010). Given conditions at the vent (mixture exit velocity, temper- ature and magmatic water content) and a wind profile, the model can solve for plume height given the eruption rate or vice versa. FPLUME can also be extended above the NBL, i.e. to solve the umbrella region semi-empirically in case of strong plumes. In case of favourable wet aggregation conditions (formation of a liquid water window inside the plume or in presence of ice at the upper regions), the aggregation model predicts an effective grain size distribution considering a single aggregated class. For the aggregation model, two test cases have been considered, the Phase-B of El Chichón 1982 eruption and the 6 May 2010 Eyjafjallajökull eruption phase. For the first case, we got reasonable agreement with the empirical Cornell parameterization using a fractal exponent of $D_{f o}=2.92$, with wet aggregation occurring under the presence of ice (as expected for large strong plumes). For the second case, we could reproduce the observed total mass fraction of aggregates for plume heights between 6.7 and $8.5 \mathrm{~km}$ (a.v.l.). Wet aggregation occurs in this case within a narrow window where conditions for liquid water to form are met. In case of aggregation, results are sensitive to the fractal exponent, which may range from $D_{f o}=2.92$ to $D_{f o}=2.99$. Future studies are necessary to better understand and constrain the role of this parameter.

\section{Code availability}

The code FPLUME-1.0 is available under request for research purposes. 


\section{Appendix A: Correction factor $\hat{f}$ for mass distribution for top-hat versus Gaussian formalism}

Denoting with $R$ the top-hat radius of the plume and with $b$ the Gaussian length scale the relationship between them can be written as (e.g. Davidson, 1986)

$b^{2}=R^{2} / 2$

Assuming a Gaussian profile for the concentration, $C(r)$, the mean value between $r=0$ (where the concentration is maximum) and $r=R$ is

$\langle C\rangle=C_{0} / R^{2} \int_{0}^{\infty} r \exp \left(-r^{2} / b^{2}\right) d r=$

$C_{0} /\left(2 b^{2}\right) \int_{0}^{\infty} r \exp \left(-r^{2} / b^{2}\right) d r=0.25 C_{0}$

that implies $\hat{C}=0.25 C_{0}$. Following similar calculations we have also

$$
\begin{aligned}
& \left\langle C^{2}\right\rangle=C_{0}^{2} / R^{2} \int_{0}^{\infty} r \exp \left(-2 r^{2} / b^{2}\right) d r= \\
& C_{0}^{2} /\left(2 b^{2}\right) \int_{0}^{\infty} r \exp \left(-2 r^{2} / b^{2}\right) d r=0.125 C_{0}^{2}, \\
& \left\langle C^{3}\right\rangle=C_{0}^{3} / R^{2} \int_{0}^{\infty} r \exp \left(-3 r^{2} / b^{2}\right) d r= \\
& C_{0}^{3} /\left(2 b^{2}\right) \int_{0}^{\infty} r \exp \left(-3 r^{2} / b^{2}\right) d r=0.0833 C_{0}^{3} .
\end{aligned}
$$

Therefore, if we use average (top-hat) variables in Eq. (34) we need to keep in mind that concentration appears in the nonlinear terms and therefore we should use the following correction factors:

$\hat{f}_{2}=\frac{\left\langle C^{2}\right\rangle}{\hat{C}^{2}}=\frac{0.125 C_{0}^{2}}{\left(0.25 C_{0}\right)^{2}}=\frac{0.125 C_{0}^{2}}{0.0625 C_{0}^{2}}=2$,

$\hat{f}_{3}=\frac{\left\langle C^{3}\right\rangle}{\hat{C}^{3}}=\frac{0.0833 C_{0}^{2}}{0.015625 C_{0}^{3}}=5.33$,

and so on $(\langle\cdot\rangle$ denotes the average using the top-hat filter, e.g. $\hat{C}=\langle C\rangle)$. Because terms in Eq. (34) scale with concentration with a power of two we need to account for a correction factor $\hat{f}=\hat{f}_{2}$. The factor $\hat{f}$ can be also used to correct underestimation of Eulerian timescale with respect Lagrangian timescale (e.g. Dosio et al., 2005).

\section{Appendix B: Computation of $\boldsymbol{n}_{\text {tot }}$}

Consider a particle grain size distribution discretized in $n$ bins of width $\Delta \Phi_{j}$ with the bin centre at $\Phi_{j}$ and where $\Phi_{j a}$ and $\Phi_{j b}$ are the bin limits (i.e. $\Delta \Phi_{j}=\Phi_{j b}-\Phi_{j a}$ ). The number of particles per unit volume in the bin $\Phi_{j}$ (assuming spherical particles) is

$n\left(\Phi_{j}\right)=\int_{\Phi_{j a}}^{\Phi_{j b}} \frac{6 C(\Phi)}{\pi \rho(\Phi) d^{3}(\Phi)} d \Phi$.

Considering that $d(\Phi)=d_{*} 2^{-\Phi}=d_{*} e^{-\Phi \log 2}$ and the tophat formalism, the above expression can be approached as

$$
\begin{aligned}
& n\left(\Phi_{j}\right) \approx \frac{6 \hat{C}_{j}}{\pi \rho_{j} d_{*}^{3} \Delta \Phi_{j}} \int_{\Phi_{j a}}^{\Phi_{j b}} e^{3 \Phi \log 2} d \Phi \\
& =\frac{1}{3 \log 2}\left(\frac{6 \hat{C}_{j}}{\pi \rho_{j} d_{*}^{3} \Delta \Phi_{j}}\right)\left[e^{3 \log 2 \Phi_{j b}}-e^{3 \log 2 \Phi_{j a}}\right] .
\end{aligned}
$$

Adding the contribution of all bins, this yields to

$$
\begin{aligned}
& n_{\mathrm{tot}}=\frac{1}{3 \log 2 d_{*}^{3}} \sum_{j}\left(\frac{6 \hat{C}_{j}}{\pi \rho_{j} \Delta \Phi_{j}}\right) \\
& {\left[e^{3 \log 2\left(\Phi_{j}+\Delta \Phi_{j} / 2\right)}-e^{3 \log 2\left(\Phi_{j}-\Delta \Phi_{j} / 2\right)}\right]}
\end{aligned}
$$

or, in terms of particle diameter,

$n_{\mathrm{tot}}=\frac{1}{3 \log 2} \sum_{j}\left(\frac{6 \hat{C}_{j}}{\pi \Delta \Phi_{j} \rho_{j}}\right)\left[\frac{1}{d_{a j}^{3}}-\frac{1}{d_{b j}^{3}}\right]$,

which is Eq. (42). 
Acknowledgements. This work was partially supported by the MED-SUV Project funded by the European Union (FP7 grant agreement no. 308665). We acknowledge C. Bonadonna for providing grain size data for the Eyjafjallajökull test case. We thank T. Esposito Ongaro and two anonymous reviewer for their constructive comments.

Edited by: R. Sander

\section{References}

Arason, P., Petersen, G. N., and Bjornsson, H.: Observations of the altitude of the volcanic plume during the eruption of Eyjafjallajökull, April-May 2010, Earth Syst. Sci. Data, 3, 9-17, doi:10.5194/essd-3-9-2011, 2011.

Arastoopour, H., Wang, C., and Weil, S.: Particle-particle interaction force in a dilute gas-solid system, Chem. Eng. Sci., 37, 1379-1386, doi:10.1016/0009-2509(82)85010-0, 1982.

Bemporad, G. A.: Simulation of round buoyant jets in a stratified flowing environment, J. Hydr. Eng., 120, 529-543, 1994.

Bonadonna, C., Genco, R., Gouhier, M., Pistolesi, M., Cioni, R., Alfano, F., Hoskuldsson, A., and Ripepe, M.: Tephra sedimentation during the 2010 Eyjafjallajökull eruption (Iceland) from deposit, radar, and satellite observations, J. Geophys. Res.-Solid Earth, 116, B12202, doi:10.1029/2011JB008462, 2011.

Bonasia, R., Costa, A., Folch, A., Macedonio, G., and Capra, L.: Numerical simulation of tephra transport and deposition of the $1982 \mathrm{El}$ Chichón eruption and implications for hazard assessment, J. Volcanol. Geotherm. Res., 231-232, 39-49, doi:10.1016/j.jvolgeores.2012.04.006, 2012.

Brown, R., Bonadonna, C., and Durant, A.: A review of volcanic ash aggregation, Phys. Chem. Earth, 45-46, 65-78, doi:10.1016/j.pce.2011.11.001, 2012.

Bursik, M.: Effect of wind on the rise height of volcanic plumes, Geophys. Res. Lett., 28, 3621-3624, doi:10.1029/2001GL013393, 2001.

Carazzo, G., Kaminski, E., and Tait, S.: The route to self-similarity in turbulent jets and plumes, J. Fluid Mech., 547, 137-148, doi:10.1017/S002211200500683X, 2006.

Carazzo, G., Kaminski, E., and Tait, S.: On the dynamics of volcanic columns: A comparison of field data with a new model of negatively buoyant jets, J. Volcanol. Geotherm. Res., 178, 94103, doi:10.1016/j.jvolgeores.2008.01.002, 2008a.

Carazzo, G., Kaminski, E., and Tait, S.: On the rise of turbulent plumes: Quantitative effects of variable entrainment for submarine hydrothermal vents, terrestrial and extra terrestrial explosive volcanism, J. Geophys. Res., 113, B09201, doi:10.1029/2007JB005458, 2008b.

Carazzo, G., Girault, F., Aubry, T., Bouquerel, H., and Kaminski, E.: Laboratory experiments of forced plumes in a density-stratified crossflow and implications for volcanic plumes, Geophys. Res. Lett., 41, 8759-8766, doi:10.1002/2014GL061887, 2014.

Carey, S. N. and Sigurdsson, H.: Influence of particle aggregation on deposition of distal tephra from the MAy 18, 1980, eruption of Mount St. Helens volcano, J. Geophys. Res.-Solid Earth, 87, 7061-7072, doi:10.1029/JB087iB08p07061, 1982.

Charpentier, I. and Espíndola, J. M.: A study of the entrainment function in models of Plinian columns: characteristics and cal- ibration, Geophys. J. Int., 160, 1123-1130, doi:10.1111/j.1365246X.2005.02541.x, 2005.

Cornell, W., Carey, S., and Sigurdsson, H.: Computer simulation of transport and deposition of the campanian Y-5 ash, J. Volcanol. Geotherm. Res., 17, 89-109, doi:10.1016/0377-0273(83)90063X, 1983.

Costa, A., Macedonio, G., and Folch, A.: A three-dimensional Eulerian model for transport and deposition of volcanic ashes, Earth Planet. Sci. Lett., 241, 634-647, 2006.

Costa, A., Folch, A., and Macedonio, G.: A model for wet aggregation of ash particles in volcanic plumes and clouds: 1 . Theoretical formulation, J. Geophys. Res. B: Solid Earth, 115, B09201, doi:10.1029/2009JB007175, 2010.

Costa, A., Folch, A., and Macedonio, G.: Density-driven transport in the umbrella region of volcanic clouds: Implications for tephra dispersion models, Geophys. Res. Lett., 40, 1-5, doi:10.1002/grl.50942, 2013.

Costa, A., Suzuki, Y. J., Cerminara, M., Devenish, B. J., Esposti Ongaro, T., Herzog, M., Van Eaton, A. R., Denby, L. C., Bursik, M. de' Michieli Vitturi, M., Engwell, S., Neri, A., Barsotti, S., Folch, A., Macedonio, G., Girault, F., Carazzo, G., Tait, S., Kaminski, E., Mastin, L. G., Woodhouse, M. J., Phillips, J. C., Hogg, A. J., Degruyter, W., and Bonadonna, C.: Results of the eruption column model inter-comparison exercise, J. Volcanol. Geotherm. Res., accepted, 2015.

Craske, J., Debugne, A., and van Reeuwijk, M.: Shear-flow dispersion in turbulent jets, J. Fluid Mech., 781, 28-51, doi:10.1017/jfm.2015.417, 2015.

Davidson, G. A.: Gaussian versus top-hat profile assumptions in integral plume models, Atmos. Environ., 20, 417-478, 1986.

de' Michieli Vitturi, M., Neri, A., and Barsotti, S.: PLUMEMoM 1.0: A new integral model of volcanic plumes based on the method of moments, Geosci. Model Dev., 8, 2447-2463, doi:10.5194/gmd-8-2447-2015, 2015.

Degruyter, W. and Bonadonna, C.: Improving on mass flow rate estimates of volcanic eruptions, Geophys. Res. Lett., 39, L16308, doi:10.1029/2012GL052566, 2012.

Dellino, P., Mele, D., Bonasia, R., Braia, G., La Volpe, L., and Sulpizio, R.: The analysis of the influence of pumice shape on its terminal velocity, Geophys. Res. Lett., 32, n/a-n/a, doi:10.1029/2005GL023954, 2005.

Dellino, P., Dioguardi, F., Mele, D., D’Addabbo, M., Zimanowski, B., Büttner, R., Doronzo, D. M., Sonder, I., Sulpizio, R., Dürig, T., and La Volpe, L.: Volcanic jets, plumes, and collapsing fountains: Evidence from large-scale experiments, with particular emphasis on the entrainment rate, Bull. Volcanol., 76, 1-18, doi:10.1007/s00445-014-0834-6, 2014.

Devenish, B.: Using simple plume models to refine the source mass flux of volcanic eruptions according to atmospheric conditions, J. Volcanol. Geotherm. Res., 256, 118-127, doi:10.1016/j.jvolgeores.2013.02.015, 2013.

Dosio, A., Vila-Guerau de Arelano, J., and Holstlag, A.: Relating Eulerian and Lagrangian Statistics for the Turbulent Dispersion in the Atmospheric Convective Boundary Layer, J. Atmos. Sci., 62, 1175-1191, 2005.

Durant, A. J., Rose, W. I., Sarna-Wojcicki, A. M., Carey, S., and Volentik, A.: Hydrometeor-enhanced tephra sedimentation: Constraints from the 18 May 1980 eruption of Mount 
St. Helens, J. Geophys. Res.-Solid Earth, 114, B03204, doi:10.1029/2008JB005756, 2009.

Ernst, G., Sparks, R. S. J., Carey, S., and Bursik, M.: Sedimentation from turbulent jets and plumes, J. Geophys. Res., 101, 5575$5589,1996$.

Esposti Ongaro, T., Cavazzoni, C., Erbacci, G., Neri, A., and Salvetti, M.: A parallel multiphase flow code for the $3 \mathrm{D}$ simulation of explosive volcanic eruptions, Parallel Comp., 33, 541-560, doi:10.1016/j.parco.2007.04.003, 2007.

Folch, A.: A review of tephra transport and dispersal models: Evolution, current status, and future perspectives, J. Volcanol. Geotherm. Res., 235-236, 96-115, 2012.

Folch, A., Costa, A., and Macedonio, G.: FALL3D: A computational model for transport and deposition of volcanic ash, Comp. Geosci., 35, 1334-1342, doi:10.1016/j.cageo.2008.08.008, 2009.

Folch, A., Costa, A., Durant, A., and Macedonio, G.: A model for wet aggregation of ash particles in volcanic plumes and clouds: 2. Model application, J. Geophys. Res., 115, B09202, doi:10.1029/2009JB007176, 2010.

Frenklach, M.: Method of moments with interpolative closure, Chem. Eng. Sci., 57, 2229-2239, 2002.

Ganser, G. H.: A rational approach to drag prediction of spherical and nonspherical particles, Powder Technol., 77, 143-152, doi:10.1016/0032-5910(93)80051-B, 1993.

Gmachowski, L.: Calculation of the fractal dimension of aggregates, Coll. Surf. A, 211, 197-203, doi:10.1016/S09277757(02)00278-9, 2002.

Gudmundsson, M., Thordarson, T., Höskuldsson, A., Larsen, G., Björnsson, H., Prata, F., Oddsson, B., Magnüsson, E., Högnadoóttir, T., Petersen, G., Hayward, C., Stevenson, J., and Jónsdóttir: Ash generation and distribution from the April-May 2010 eruption of Eyjafjallajökull, Iceland, Nature Sci. Rep., 1-12, doi:10.1038/srep00572, 2012.

Herzog, M. and Graf, H.-F.: Applying the three-dimensional model ATHAM to volcanic plumes: Dynamic of large co-ignimbrite eruptions and associated injection heights for volcanic gases, Geophys. Res. Lett., 37, 119807, doi:10.1029/2010GL044986, 2010.

Hewett, T. A., Fay, J. A., and Hoult, D. P.: Laboratory experiments of smokestack plumes in a stable atmosphere, Atmos. Environ., 5, 767-789, doi:10.1016/0004-6981(71)90028-X, 1971.

Hindmarsh, A.: Lsode and lsodi, two new initial value ordinary differential equations solvers, Acm-Signum Newsl., 4, 10-11, 1980.

Jacobson, M. Z.: Fundamentals of atmospheric modelling, Cambridge University Press, New York, 2nd edn. edn., 828 pp., 2005.

Jullien, R. and Botet, R.: Aggregation and fractal aggregates, World Sci., Singapore, 120 pp., ISBN 9971502488, 1987.

Kaminski, E., Tait, S., and Carazzo, G.: Turbulent entrainment in jets with arbitrary buoyancy, J. Fluid Mech., 526, 361-376, doi:10.1017/S0022112004003209, 2005.

Krumbein, W. C.: Size frequency distributions of sediments, J. Sediment. Res., 4, 65-67, 1934.

Lee, J. H. and Cheung, V.: Generalized Lagrangian Model for Buoyant Jets in Current, J. Environ. Eng., 116, 1085-1106, 1990.

Mastin, L., Guffanti, M., Servranckx, R., Webley, P., Barsotti, S., Dean, K., Durant, A., Ewert, J., Neri, A., Rose, W., Schneider, D., Siebert, L., Stunder, B., Swanson, G., Tupper, A., Volentik, A., and Waythomas, C.: A multidisciplinary effort to assign realistic source parameters to models of volcanic ash-cloud transport and dispersion during eruptions, J. Volcanol. Geotherm. Res., 186, 10-21, doi:10.1016/j.jvolgeores.2009.01.008, 2009.

Morton, B. R., Taylor, G. I., and Turner, J. S.: Turbulent gravitational convection from maintained and instantaneous source, Proc. Roy. Soc. Lnd., 234, 1-23, 1956.

Murphy, D. M. and Koop, T.: Review of the vapour pressures of ice and supercooled water for atmospheric applications, Q. J. Roy. Meteorol. Soc., 131, 1539-1565, doi:10.1256/qj.04.94, 2005.

Netterville, D. D. J.: Plume rise, entrainment and dispersion in turbulent winds, Atmos. Environ. A, 1990.

Pruppacher, H. R. and Klett, J. D.: Microphysics of Clouds and Precipitation, Springer, 1st edn., 976 pp., 1996.

Rose, W. and Durant, A.: El Chichón volcano, April 4, 1982: volcanic cloud history and fine ash fallout, Nat. Hazards, 51, 363 374, doi:10.1007/s11069-008-9283-x, 2009.

Rouse, H., Yih, C. S., and Humphreys, H. W.: Gravitational convection from a boundary source, Tellus, 4, 201-210, 1952.

Schneider, D. J., Rose, W. I., Coke, L. R., and Bluth, G. J. S.: Early evolution of a stratospheric volcanic eruption cloudas observed with TOMS and AVI-IRR, J. Geophys. Res., 104, 4037-4050, 1999.

Sigurdsson, H., Carey, S., and Espindola, J.: The 1982 eruptions of El Chichón Volcano, Mexico: Stratigraphy of pyroclastic deposits, J. Volcanol. Geotherm. Res., 23, 11-37, doi:10.1016/0377-0273(84)90055-6, 1984.

Sparks, R.: The dimensions and dynamics of volcanic eruption columns, Bulletin of Volcanology, 48, 315, doi:10.1007/BF01073509, http://dx.doi.org/10.1007/ BF01073509, 1986.

Sparks, R. S. J.: Volcanic plumes, Chichester, New York, Wiley, 574 pp., 1997.

Suzuki, Y. J. and Koyaguchi, T.: A three-dimensional numerical simulation of spreading umbrella clouds, J. Geophys. Res., 114, B03209, doi:10.1029/2007JB005369, 2009.

Suzuki, Y. J. and Koyaguchi, T.: 3D numerical simulation of volcanic eruption clouds during the 2011 Shinmoe-dake eruptions, Earth Plan. Space, 65, 581-589, doi:10.5047/eps.2013.03.009, 2013.

Suzuki, Y. J. and Koyaguchi, T.: Effects of wind on entrainment efficiency in volcanic plumes, J. Geophys. Res. doi:10.1002/2015JB012208, 2015.

Suzuki, Y. J., Koyaguchi, T., Ogawa, M., and Hachisu, I.: A numerical study of turbulent behaviour in eruption clouds using a three dimensional fluid dynamics model, J. Geophys. Res., 110, B08201, doi:10.1029/2004JB003460, 2005.

Tate, P. M.: The rise and dilution of buoyant jets and their behaviour in an internal wave field, PhD. thesis, University of New South Wales, 2002.

Wang, H. and Wing-Keung Law, A.: Second-order integral model for a round turbulent buoyant jet, J. Fluid Mech., 459, 397-428, doi:10.1017/S0022112002008157, 2002.

Wilson, L.: Explosive Volcanic Eruptions, III. Plinian Eruption Columns, Geophys. J. Int., 45, 543-556, doi:10.1111/j.1365246X.1976.tb06909.x, 1976.

Wilson, L. and Huang, T. C.: The influence of shape on the atmospheric settling velocity of volcanic ash particles, Earth Planet Sci. Lett., 44, 311-324, doi:10.1016/0012-821X(79)90179-1, 1979. 
Woodhouse, M. J., Hogg, A. J., Phillips, J. C., and Sparks, R. S. J.: Interaction between volcanic plumes and wind during the 2010 Eyjafjallajökull eruption, Iceland, J. Geophys. Res.-Solid Earth, 118, 92-109, doi:10.1029/2012JB009592, 2013.

Woods, A. W.: Moist convection and the injection of volcanic ash into the atmosphere, J. Geophys. Res., 98, 17627, doi:10.1029/93JB00718, 1993.
Woods, A. W. and Kienle, J.: The dynamics and thermodynamics of volcanic clouds: Theory and observations from the April 15 and April 21, 1990 eruptions of Redoubt Volcano, Alaska, J. Volcanol. Geotherm. Res., 62, 273-299, 1994.

Xiong, C. and Friedlander, S. K.: Morphological properties of atmospheric aerosol aggregates, P. Natl. Acad. Sci. USA, 98, 1185111856, doi:10.1073/pnas.211376098, 2001. 